\title{
Experiencias relacionadas con riesgos no evidentes en puentes existentes
}

\author{
Experiences Related to Non-Evident Risks in Existing Bridges \\ Fco. Javier León González ${ }^{\mathrm{a}}$ Hugo Corres Peiretti ${ }^{\mathrm{a}}$ \\ a Drs. Ing. de Caminos, Canales y Puertos \\ ETS de Ingenieros de Caminos, Canales y Puertos. UPM; FHECOR
}

Recibido el 15 de diciembre de 2020; aceptado el 16 de abril de 2021

\section{RESUMEN}

Se presenta en este artículo una relación de experiencias vividas por los autores en el ejercicio profesional. Tales vivencias, algunas relacionadas con aspectos ya conocidos pero otras no tanto, han animado a los autores a promover una calificación de las estructuras en función de un indicador asociado al riesgo. No es un planteamiento asociado a estudios de fiabilidad o a la gestión analítica del riesgo, sino una aproximación para que los gestores de los puentes, que han de administrar un patrimonio muy extenso, puedan disponer de una relación jerarquizada con arreglo a criterios simplificados y prácticos.

PALABRAS CLAVE: Aspectos críticos, amenazas, durabilidad, gestión de puentes.

(C) 2021 Asociación Española de Ingeniería Estructural (ACHE). Publicado por Cinter Divulgación Técnica S.L. Todos los derechos reservados.

\section{ABSTRACT}

This paper contains a description of some experiences achieved by the authors regarding critical aspects of existing bridges. Some of these lessons are related to well-known causes, but some others are perhaps new for our colleagues. Based on these experiences, it is the aim of the authors to promote the elaboration of an index to qualify bridges according to a practical approach to handle with detected risks. It is not the purpose of this paper to enter in reliability analysis, but to help administrations to organize in a hierarchy the heritage of bridges they are responsible for.

KEYWORDS: Critical aspects, hazards, durability, bridge management systems.

(C) 2021 Asociación Española de Ingeniería Estructural (ACHE). Published by Cinter Divulgación Técnica S.L. All rights reserved.

1.

\section{PREÁMBULO}

En mayo de 2019, en el contexto de la Conferencia Internacional sobre la Gestión de la Conservación de los Puentes ${ }^{1}$, Javier Rui-Wamba impartió la conferencia titulada Los puentes y sus circunstancias. En opinión de los autores de este artículo, las incertidumbres son también circunstancias, en el más pleno sentido orteguiano de la expresión. De eso se trata en este escrito:

1 Tuvo lugar en Sevilla, organizado por ATC-AIPCR, entre el 20 y el 21 de mayo de 2019.

* Persona de contacto / Corresponding author: Correo-e / email: jlg@fhecor.es (Fco. Javier León) de explicar estas experiencias a la hora de detectar los riesgos, no siempre evidentes, en los puentes. Parece que la cuestión está adquiriendo, justamente, creciente relevancia y es oportuno que se vaya configurando un corpus de conocimiento, como ya se hace desde foros como la $f i b$, en cuyo seno el segundo de los autores coordina la elaboración del Código Modelo 2020 [1], llamado a tratar en pie de igualdad las construcciones nuevas y las existentes.

Se trata, conviene advertirlo desde el principio, de riesgos que trascienden lo puramente técnico, en el sentido convencional, afectando a un plano superior: el del valor patrimonial de los puentes, al que se refiere el documento [2], redactado en el seno de un grupo de trabajo coordinado por el segundo de los autores. Porque se habla del riesgo de perder obras cuyo 


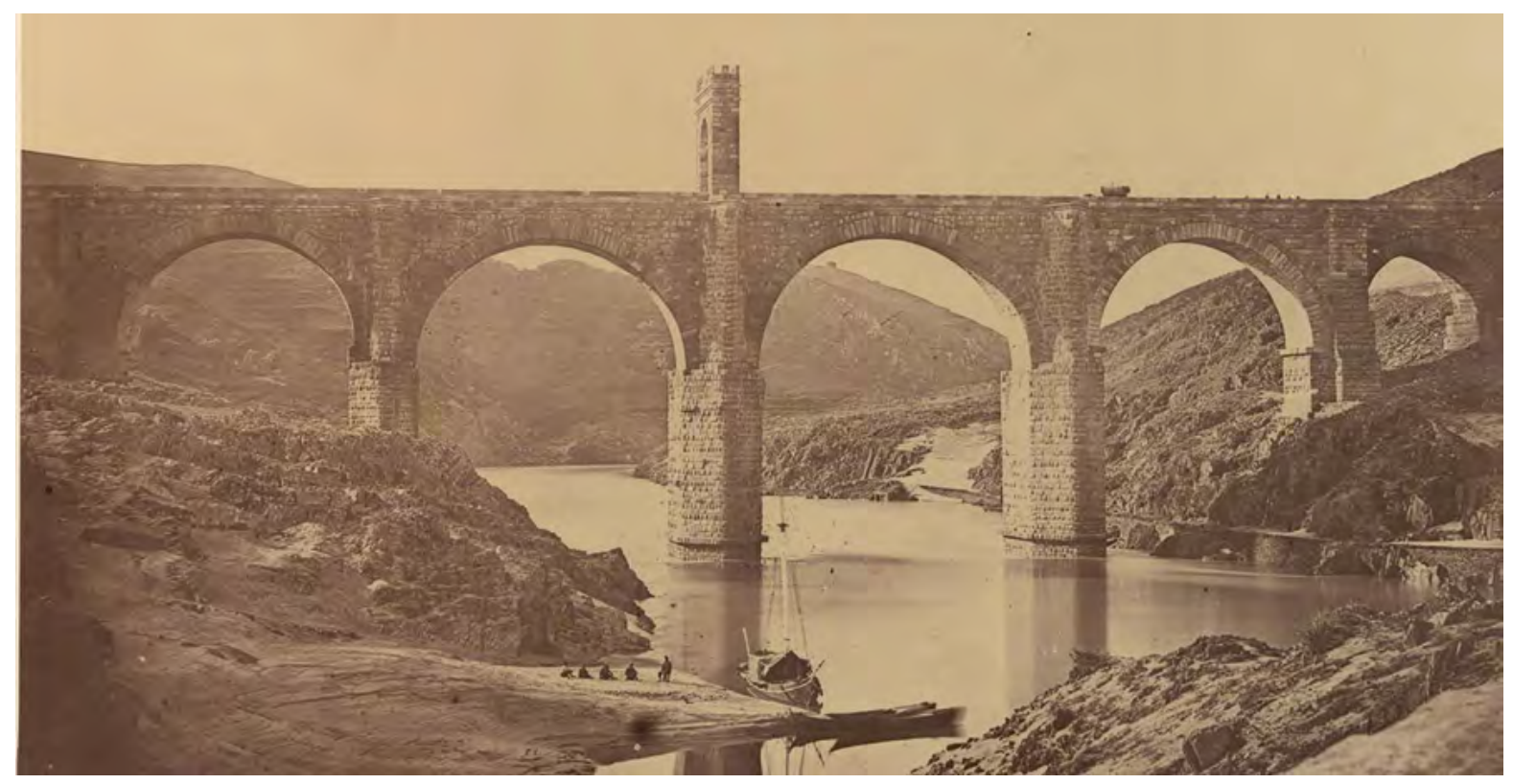

Figura 1. Puente de Alcántara. Clifford, 1860. Biblioteca de la ETSICCP-UPM.

valor está muy por encima del utilitario y que constituyen un bien que es patrimonio de la humanidad, como el puente de Alcántara (figura 1), aunque, sorprendentemente, no tenga tal calificativo oficial. Ese valor patrimonial trasciende al del gremio de los ingenieros o de los historiadores para formar parte de la historia.

Se trata en este artículo de compartir experiencias con el fin de minimizar los errores humanos que se derivan de la falta de conocimiento en las fases de proyecto, construcción, inspección y rehabilitación. El peor riesgo es el no identificado.

\section{2.}

\section{PROPUESTA DE TRATAMIENTO DE LOS RIESGOS}

Está ya muy arraigada la definición cuantitativa de riesgo que, de manera quizás simplista, se expresa como el producto de la probabilidad de que se produzca el fallo y de las consecuencias del mismo ${ }^{2}$. La figura 2 ejemplifica, de manera cualitativa, esa situación. Un puente, construido en un momento dado y considerado como aceptable por ajustarse, convencionalmente, a un marco reglamentario o por haber exhibido un comportamiento correcto a lo largo del tiempo (punto A en la figura 2), puede pasar a una situación inaceptable (punto B) sin más que dejar que el tiempo actúe inexorablemente sobre sus materiales y sus condiciones de contorno (el lecho del río, la cimentación), incluso suponiendo que no se modifican las consecuencias del potencial fallo. $\mathrm{O}$ puede pasar al punto $\mathrm{C}$, asociado a la situación en la que, incluso suponiendo que no varía con el tiempo la probabilidad de fallo, las consecuencias de este se hagan inaceptables. La situación más probable, casi siempre con menor recorrido temporal además, es la de que el puente pase a una situación intolerable (punto D) porque tan-

2 La tesis doctoral de P. Tanner [3] es un magnifico documento con el que iniciarse en estos conceptos. to la probabilidad de fallo, por deterioro, uso o por mayor exposición a las acciones accidentales (sismo, riadas, etc.), como las consecuencias del colapso, por aumento de las primas de seguro (el mayor precio de la vida humana, dicho de manera grosera) o la mayor sensibilidad hacia el patrimonio construido, hayan ido creciendo.

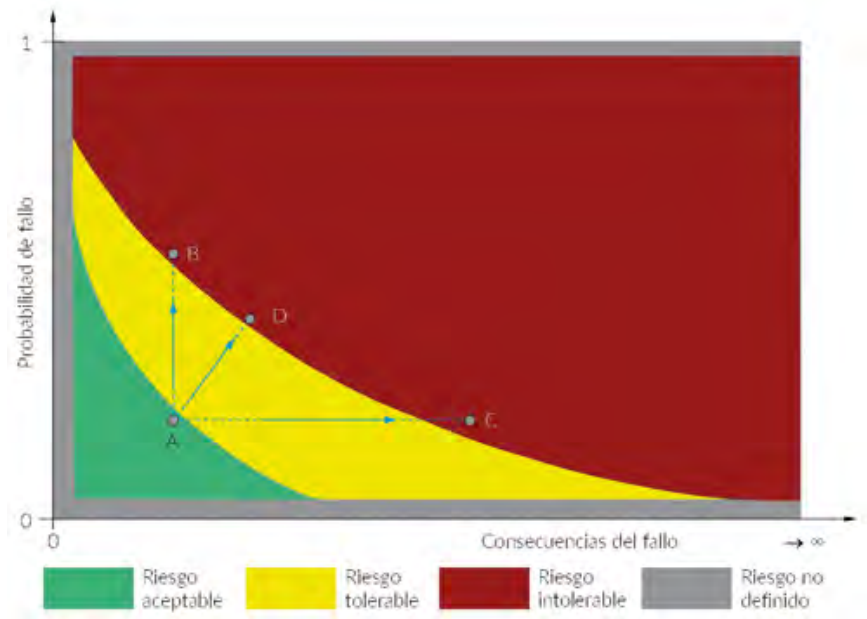

Figura 2. Tomada, con aportaciones de los autores, de la pág. 37 de [4].

En este texto se enuncian algunas de las situaciones que ejemplifican ambas situaciones y que, en opinión de los autores, deben incluirse en la gestión del patrimonio de puentes. Tanto las abscisas como las ordenadas de la figura 2 son de difícil cuantificación, como es bien sabido. Por esa razón, se adopta el planteamiento ingenieril expresado en la figura 3, en la que se han discretizado en "categorías" tanto las consecuencias como las probabilidades de fallo, a semejanza de lo que se plantea, por ejemplo, en los Eurocódigos. Así, la tabla 1 presenta una adaptación a los puentes de la correspondiente tabla del Eurocódigo 0 [5]. Como se puede observar, la probabilidad de fallo 
se ha categorizado en valores crecientes de 1 a 3 , de forma que el "riesgo" es

$r=p \times c$

que resulta en un escalar entre 1 y 9 . En (1) $r, p$ y $c$ representan, respectivamente, las categorías de riesgo, probabilidad de fallo y consecuencias del mismo. Naturalmente, esto es convencional, como lo es el citado contexto reglamentario europeo. Se trata, conviene subrayarlo, de una aproximación de jerarquización por indicadores a un problema que admite un planteamiento más riguroso que se derivaría de análisis de fiabilidad y de seguridad implícita, que no es el objetivo de esta propuesta.

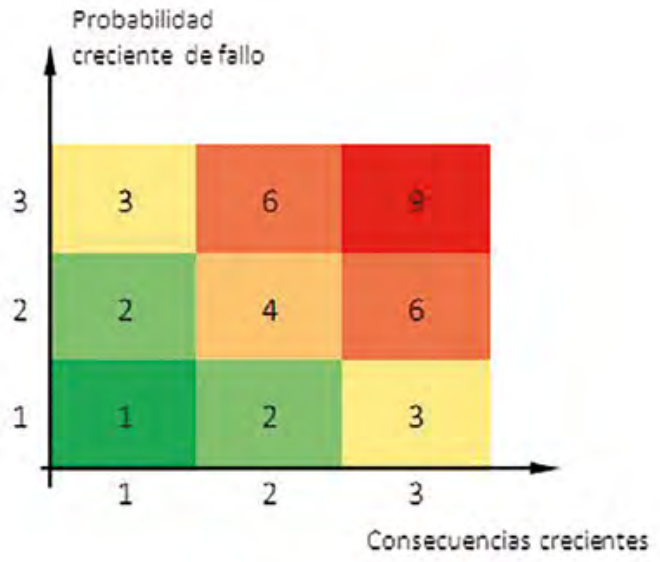

Figura 3. Matriz de riesgos asociada a la categorización de las probabilidades de fallo y las consecuencias asociadas, con los colores propios de los conocidos criterios "semáforo". Propuesta de los autores.

TABLA 1.

Clases de consecuencia propuestas para los puentes a partir del Eurocódigo 0 [3]

\begin{tabular}{ll}
\hline Clases de consecuencias & Ejemplos \\
$3(\mathrm{CC})$ & Viaducto de grandes proporciones con elevadas \\
& IMD e IMDp, con edificios habitados situados \\
& bajo su proyección o área de influencia inmedia- \\
& ta, o con cruce sobre otras vías de alta capacidad \\
& y líneas férreas de transporte de viajeros o vías \\
& fluviales. En caso de colapso, el número de vícti- \\
& mas sería elevado y las consecuencias económicas \\
& serían muy importantes. \\
& \\
& Puente o viaducto en vías de gran capacidad \\
& (autopistas o autovías), con otras vías bajo ella \\
& (carreteras, autopistas o vías férreas) pero no tan \\
& importantes y sin edificios o industrias afectadas \\
& en su proyección o área de influencia inmediata. \\
& Se incluyen los pasos superiores que den soporte \\
& a carreteras o vías férreas. En caso de colapso las \\
& consecuencias serían moderadamente graves. \\
& \\
& Resto de obras de paso, obras de drenaje o pasos \\
& inferiores de reducida intensidad de tráfico. \\
& En caso de colapso las consecuencias estarían \\
& acotadas.
\end{tabular}

Tanto la probabilidad como la consecuencia del fallo admiten un tratamiento numérico que no se expone aquí, pero que está relacionado con valores categorizados de $p$ y $c$, afectados por coeficientes $\lambda$ de ponderación, pues no todos los aspectos o factores tienen la misma trascendencia en términos de proba- bilidad y consecuencia. Una forma de considerar tal ponderación es la descrita en [6], con el método de Saaty, a partir de la aportación de M. Tena que también se encuentra en [2].

Sin ánimo de ser exhaustivos, se presentan aquí algunos de los aspectos o factores susceptibles de ser considerados, bien entendido que cada uno de ellos admite, casi siempre, el análisis de las probabilidades y de las consecuencias del fallo en los términos expuestos. Muchas de las amenazas que se describen a continuación son bien conocidas. Otras, en opinión de los autores, no tanto.

\section{3.}

\section{SUSCEPTIBILIDAD FRENTE A ACCIDENTES QUE AFECTEN A LA ESTRUCTURA}

Si bien la probabilidad de un accidente no equivale a la probabilidad de fallo de la estructura, se acepta este enfoque en un planteamiento de jerarquización por indicadores. Si la estructura está situada sobre una vía inferior que es una carretera, la probabilidad de accidente es tanto más elevada si hay pilas intermedias y calzadas duplicadas ( $p=2$ y 3 , respectivamente, con $p=1$ si se trata de vías pecuarias o caminos vecinales), como muestra el frecuente impacto de vehículos que no respetan los gálibos (figuras 4 y 5). Si la estructura cuenta con pilas intermedias sobre una vía férrea sin contracarriles o una vía navegable sin duques de alba $p=3$. Si no hay vías inferiores, $\lambda=0$, lo que equivale a decir que este factor no interviene, como es lógico. La experiencia demuestra que la frecuencia de ese tipo de accidentes es reducida, aunque sus consecuencias suelen ser muy importantes: $c=3$ en caso de vías importantes, con valores más pequeños ( $c=1$ o 2 si se trata de vías de menor importancia), admitiéndose la tabla 1 como referencia.

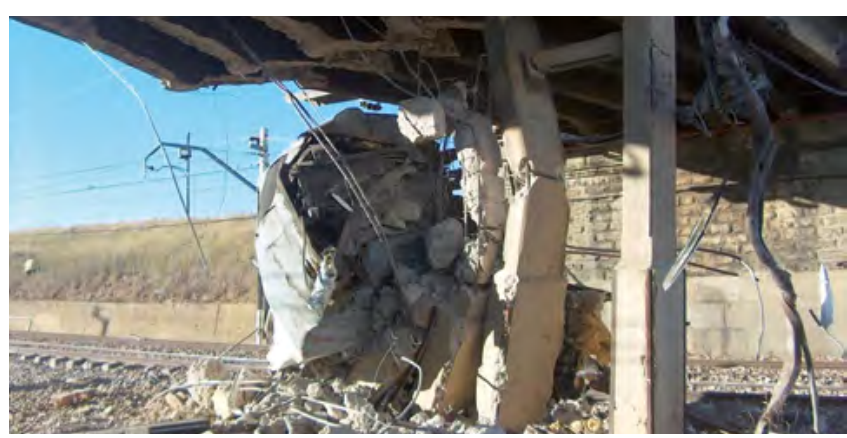

Figura 4. Impacto de un convoy ferroviario contra la pila de un puente en Villada, Palencia. 21 de agosto de 2006. Foto cortesía de ADIF.
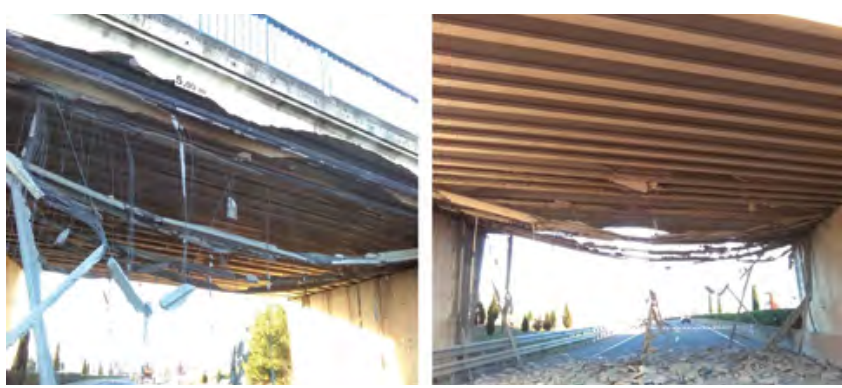

Figura 5. Impacto de un camión en Navarra en febrero de 2019. Foto de FHECOR. 
4.

\section{SUSCEPTIBILIDAD FRENTE A LA SOCAVACIÓN}

La probabilidad de ocurrencia de este tipo de fallo es mayor en los puentes de piedra o ladrillo dado que, cuando se construyeron, tanto los conocimientos como los medios constructivos no hacían posible la construcción de cimentaciones profundas. La probabilidad de fallo es aún mayor en puentes sobre ramblas de caudal muy irregular (figura 6). Para esos casos, extensibles a los puentes construidos hasta mediados del s. XX aunque sean de hormigón (figura 7 , en la que se muestra, en el croquis de la derecha, que tienen más probabilidad de afección estructural las estructuras isostáticas que las hiperestáticas), cabría asignar $p=3$ salvo que se tenga constancia fehaciente de que están cimentados sobre roca o que se han recalzado hasta un estrato profundo, considerándose $\lambda=0$ (coeficiente de ponderación de la clase de probabilidad) en tales casos.

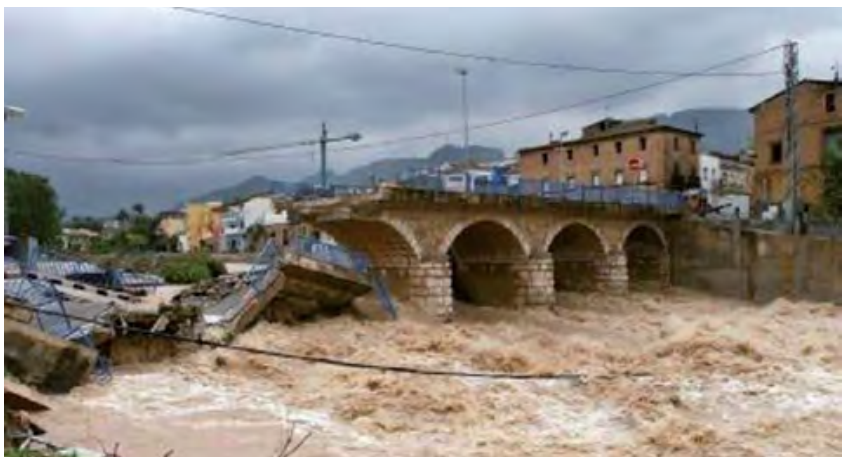

Figura 6. Hundimiento del puente de Beniarbeig (Alicante), el 11 de octubre de 2007.
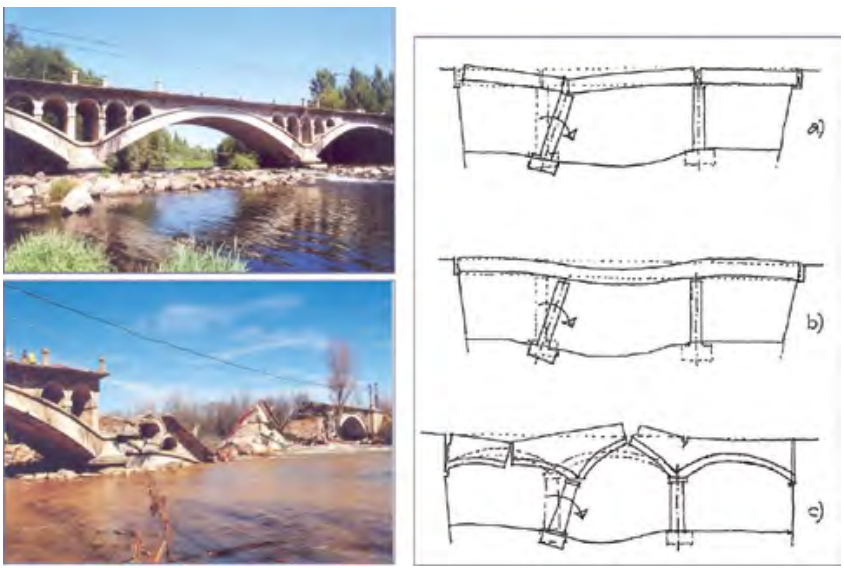

Figura 7. Puente sobre el Órbigo en Veguellina de Órbigo. Marzo de 2001. Influencia del esquema estático. Trabajo de los autores.

Sin embargo, como es sabido, lo más frecuente es que se carezca de datos relativos a la cimentación. Para discriminar un poco más, es posible distinguir los casos en que haya más o menos pilas en cauce o que este esté regulado aguas arriba o se efectúe un mantenimiento regular de riberas, pero su detalle excede los límites de este artículo.

Las consecuencias dependen del tipo de vía, obviamente, pero son mayores en el caso de puentes de arcos o bóvedas con pilas que no puedan resistir empujes desequilibrados al perderse un vano, como se puso de manifiesto en abril de 2020 en Albano-Magra (Italia). La cuestión tiene que ver también con la robustez, que se trata más adelante (figuras 34 y 36), lo que constituye un ejemplo de cómo se pueden producir concomitancias entre factores. A veces, sin embargo, se dan circunstancias inverosímiles, como las de la figura 8, en la que el equilibrio, precario, es fruto de la casualidad. Cuando se dan esas situaciones (algo parecido sucede con el caso de la figura 4) el técnico debe preguntarse qué mecanismos resistentes se pueden movilizar para explicar lo inexplicable con los argumentos convencionales. Se trata de lo que en el MC-2020 [1] se denota como "hidden mechanisms" que, por supuesto, no tienen nada de esotérico y sí algunas enseñanzas con las que ilustrar el progresivo conocimiento de la mecánica estructural.

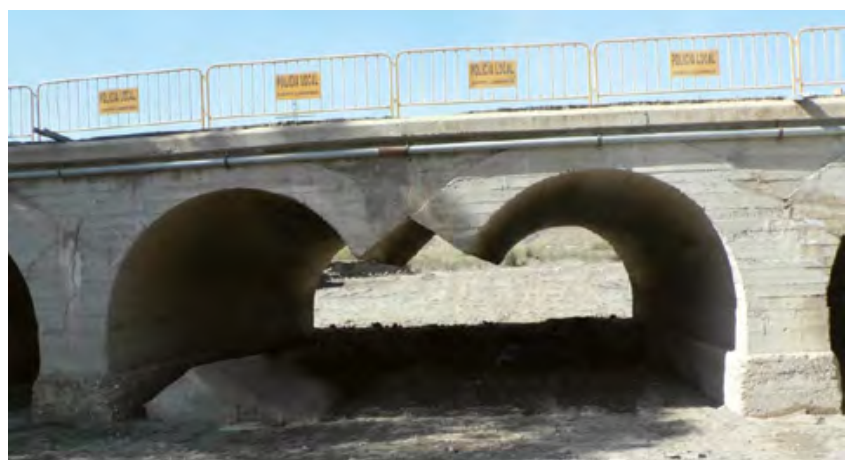

Figura 8. Puente en Puerto Lumbreras, 1 de octubre de 2012. Foto de los autores. A la izquierda se observa la pila socavada y volcada, con los arranques de las dos bóvedas acodalados precariamente entre sí.

\section{5.}

\section{INCERTIDUMBRE SOBRE LAS CARGAS PERMANENTES}

Uno de los aspectos más fáciles de controlar, aunque escasamente documentado en la práctica, es el del espesor del paquete de firmes o de los recrecidos bajo este. Este sobre-espesor afecta negativamente a la seguridad estructural, como es fácil deducir (figura 9).

Podrían asociarse a $\lambda=0$ o $p=3$ (sin graduación intermedia) en los casos en que el dato esté consignado en el inventario y de que no lo esté, respectivamente.

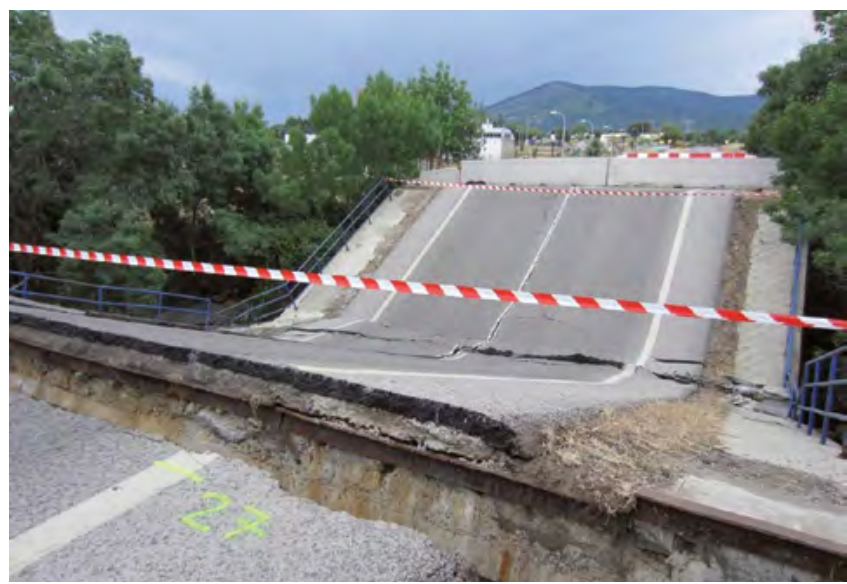

Figura 9. Ejemplo de puente con $22 \mathrm{~cm}$ de exceso de pavimento. Puente de la M-527 sobre el río Guadarrama (29 de mayo de 2015). Foto de los autores. 
Se trata de un dato de gran importancia que tiene efectos contradictorios. El paquete de firmes confiere rigidez porque se trata de un aglomerado que viene a comportarse como un hormigón, aunque con menor módulo de deformación, que aporta un incremento de la inercia al estar adherido (sin cuantificar tal adherencia). Un paquete de firmes que sea del orden del 5\% del canto del tablero equivale, grosso modo, a un incremento de rigidez del orden del 5\%. Si el espesor es del 10\%, la rigidez crece en torno a un $15 \%$. Si el espesor equivale al 16\% (puente de la figura 9) la rigidez aumenta en un $25 \%$. Eso explica un comportamiento en servicio mejor del que se deduce de análisis convencionales, pero no da más capacidad resistente en agotamiento, dado que es una carga muerta en cuanto falla la adherencia en la interfaz losa - pavimento o recrecido. En puentes ferroviarios el recrecido de la banqueta de balasto es igualmente frecuente con efectos equiparables, aunque con matices diferenciados respecto a los aglomerados de los puentes de carretera.

La figura 10 pretende explicar cualitativamente la importancia del fenómeno, que debe alertar a las administraciones responsables. Se trata de explicar que el paso de vehículos especiales muy pesados sobre estructuras proyectadas con trenes de carga ya antiguos, pero con paquetes de firmes de alguna entidad, no haya provocado deformaciones ( $\mathrm{u}$ otros daños) como cabría esperar. El diagrama muestra los diagramas momento-curvatura de una sección representativa del tablero para la estructura proyectada, sin aditamentos resistentes (trazo continuo en azul), y para la estructura que, de facto, tiene un pavimento añadido que le da más canto, más rigidez y mayor momento resistente, siempre que el pavimento esté adherido, naturalmente.

En efecto, para un momento total solicitante $M_{v e}$, que incluye la acción del peso propio, las cargas permanentes y el vehículo especial, la curvatura que se producirá si el pavimento está adherido será $(1 / r)_{p a v}$ mientras que el valor esperado, $(1 / r)^{\text {pav }}$, sería superior. Las flechas, integral de los giros y estos de las curvaturas, serán también menores, dando la falsa impresión de un correcto comportamiento resistente.

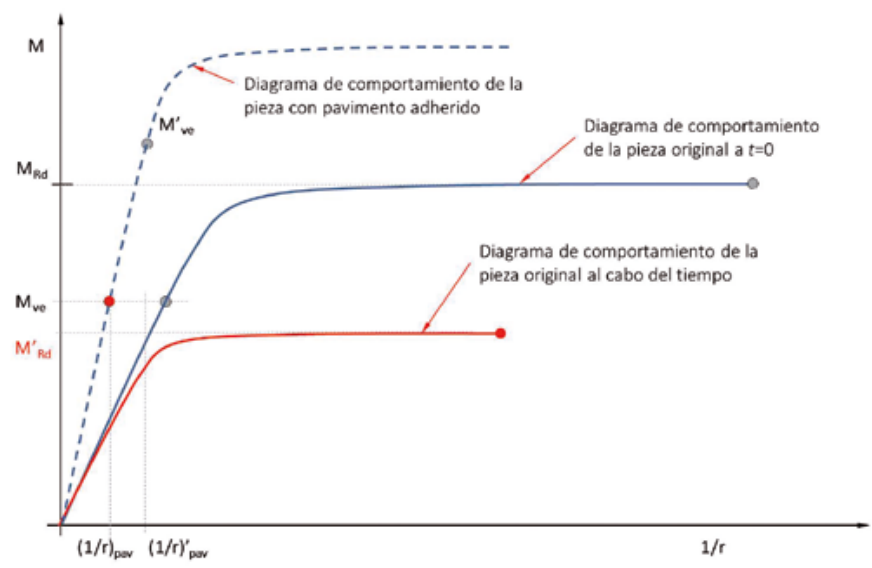

Figura 10. Diagramas momento-curvatura de piezas sin recrecido, con él y previsible estado final. Diagrama de los autores.

Podría suceder incluso que el comportamiento fuese muy lineal para momentos solicitantes $M_{v e}^{\prime}$ (de un vehículo especial) tales que, sin haberse detectado, sean mayores que la capacidad resistente para la que fue proyectado el puente. La amenaza latente es que, si por cualquier razón, entre otras el paso repetido de vehículos especiales o del tráfico normal, acaba por fallar la adherencia entre la cara superior del tablero y el paquete de firmes añadido, la estructura colapse súbitamente (redistribuciones y margen de seguridad aparte) porque $M_{v e}^{\prime}>M_{R d}$.

Pero incluso en el escenario anterior, con $M_{v e}<M_{R d}$, se puede producir el fallo de adherencia, pasando la estructura a tener, más o menos dúctilmente, una tendencia a la deformación. Además, si $M_{v e}$ se repite y los materiales han entrado en la zona de comportamiento no lineal, no puede ya asegurarse que la estructura, tras el paso del vehículo especial, esté en condiciones reglamentariamente aceptables.

Esa es una de las razones por las cuales se debe ser renuente a aceptar como válido el argumento de que ya pasó por la estructura un transporte especial similar (o el tráfico cotidiano), si no va acompañado de una estimación de la capacidad portante (lo que exige una inspección especial) o, al menos, una determinación del espesor del paquete de firmes.

\section{6.}

\section{INCERTIDUMBRE SOBRE LOS TRENES DE CARGA DE PROYECTO Y CAPACIDAD ADMISIBLE SEÑALIZADA}

Se acaba de hacer mención al caso de puentes proyectados para unos trenes de carga diferentes de los más modernos. Además, es frecuente que las administraciones responsables tengan que enfrentarse a la necesidad de señalizar explícitamente la carga máxima que puede pasar sobre los puentes. Es cotidiana asimismo la necesidad de pronunciarse acerca del paso de vehículos especiales (los que sobrepasan la masa máxima contemplada en el Reglamento General de Circulación [7]). La figura 11 muestra la carga máxima señalizada (justificadamente) en el puente de Hierro de Logroño antes de la intervención de 2008-09 y el ejemplo superpuesto (de otro puente en otra ciudad) de señalización de la carga máxima que tiene peor defensa desde el punto de vista de la racionalidad estática, aunque pueda haber otras razones vinculadas a la frecuencia.

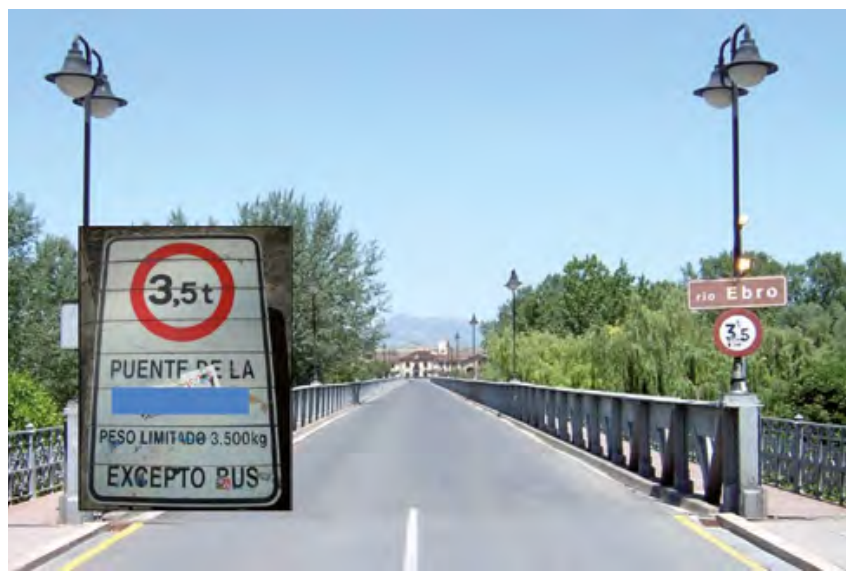

Figura 11. Ejemplos de señalización de carga máxima. Fotos de los autores.

Tal limitación debería estar vinculada, en primera instancia, a la del tren de cargas de proyecto de la estructura. Así, salvo que el puente tenga ya explicitada la limitación de la carga máxima y 
haya otras razones achacables al deterioro, cabe pensar en $p=1$ si el puente de carretera está actualizado a la Instrucción vigente o si fue construido después de 1956. Se incluyen también los puentes de bóvedas de fábrica independientemente de su fecha de construcción, que no de su estado, dado que en estos las sobrecargas son insignificantes con relación a las permanentes. El valor de $p$ pasa a 2 si el puente fue construido entre 1925 y 1956 y es de 3 si es anterior a 1925. La referencia [8] contiene una síntesis de gran interés acerca de los trenes de carga en puentes de carretera (figura 12). Hasta la utilización de los trenes envolventes (a partir de 1956) las pruebas de carga se materializaban con los mismos trenes de carga con los que se proyectaban los puentes (croquis de la parte inferior de la figura 12 tomado de [8]).

Queda por saber, obviamente, la fecha de construcción del puente. Ese dato no siempre es inmediato, pero es muy importante. En las referencias [10], [11] y [12 $]^{3}$ los autores ya destacaron la importancia de conocer la historia de los puentes, en general, y la de cada uno en particular. La referencia [13], de R. del Cuvillo ${ }^{4}$, contiene muy valiosa información para deducir las capacidades resistentes $R_{d}$ y compararlas con las solicitaciones $E_{d}$ (que se deducen con [8]).

En el caso de los puentes ferroviarios, de sobrecargas mayores en el pasado que en el presente (las grandes locomotoras de vapor eran más pesadas que las actuales), las probabilidades de excedencia son menores y puede tomarse $p=1$.

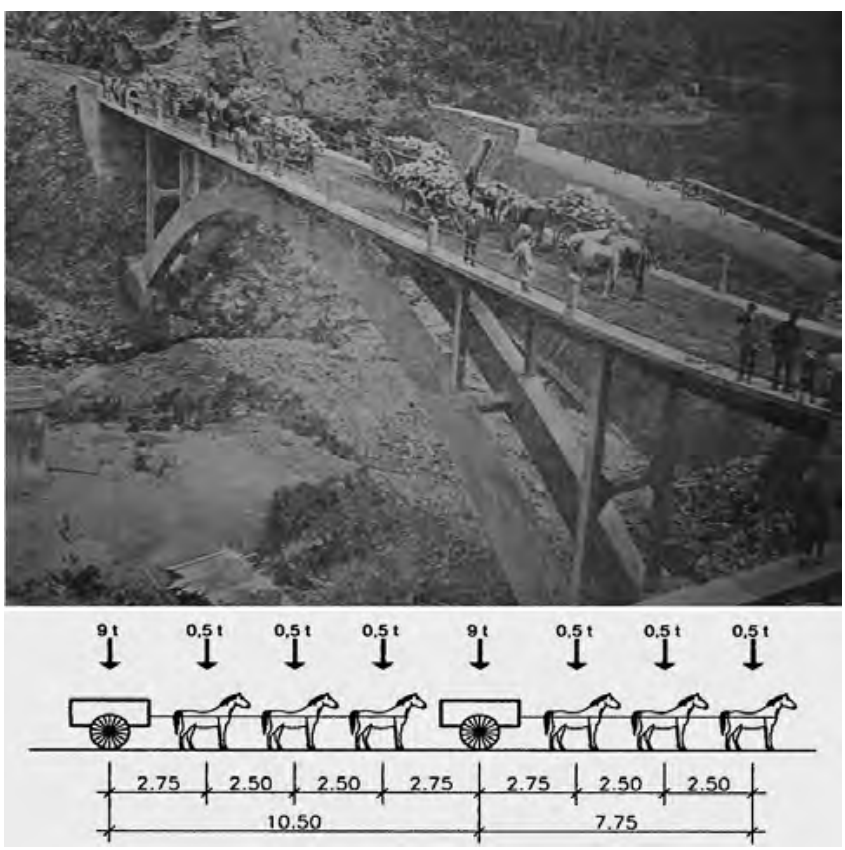

Figura 12. Prueba de carga del puente de la Presa (Goizueta, Navarra) en 1916 (Alfonso Peña Boeuf, [9]).

La cuestión, que ha sido objeto de chanzas más o menos fáciles (figura 13), es de importancia obvia y de potenciales conse-

3 La presentación del documento [12] tuvo lugar en un día en el que los aspectos históricos de la ingeniería se convirtieron en el centro del debate, lo que no es frecuente.

4 Ramón del Cuvillo (1926-2012) fue pionero en España en la implantación de sistemas de gestión de puentes, siendo autor de los primeros documentos para sistematizar inventarios e inspecciones principales [14]. cuencias muy serias, que serían objeto de clasificación como se indica en la tabla 1 .

Otra amenaza, indirectamente vinculada a los trenes de carga, es la que comportan los usos inadecuados de ciertas partes de los puentes, especialmente los más antiguos y estrechos, que tenían aceras para peatones, que no para el paso de vehículos, y que se han habilitado sin comprobaciones suficientes, para el tráfico rodado. Es el caso de la figura 14. Cabe asignar $p=3$ y consecuencias de fallo como en la tabla 1 .

\section{Dos muertos al derrumbarse un puente colgante con tres vehículos cerca de Toulouse}

El viaducto cedio bajo el enorme peso de un camión de 44 toneladas, más del doble de lo permitido
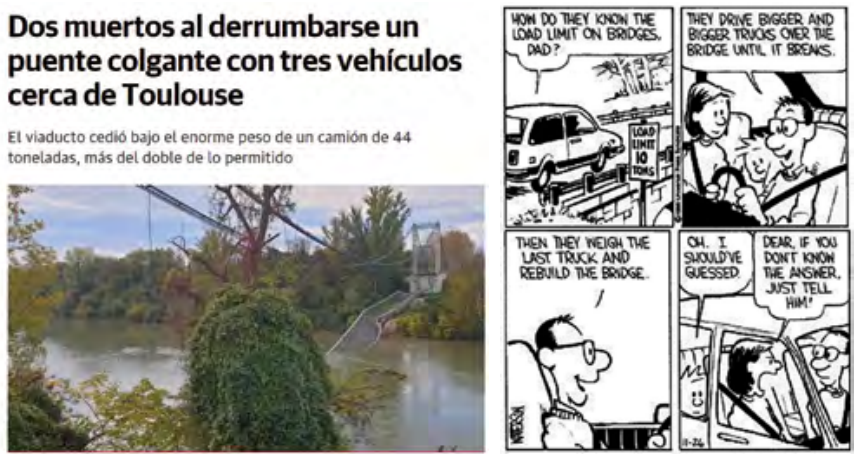

Figura 13. Viñeta tomada de [15] y noticia de un accidente frente al paso de un vehículo pesado cerca de Toulouse, Francia, sobre el río Tarn (1935) [16].
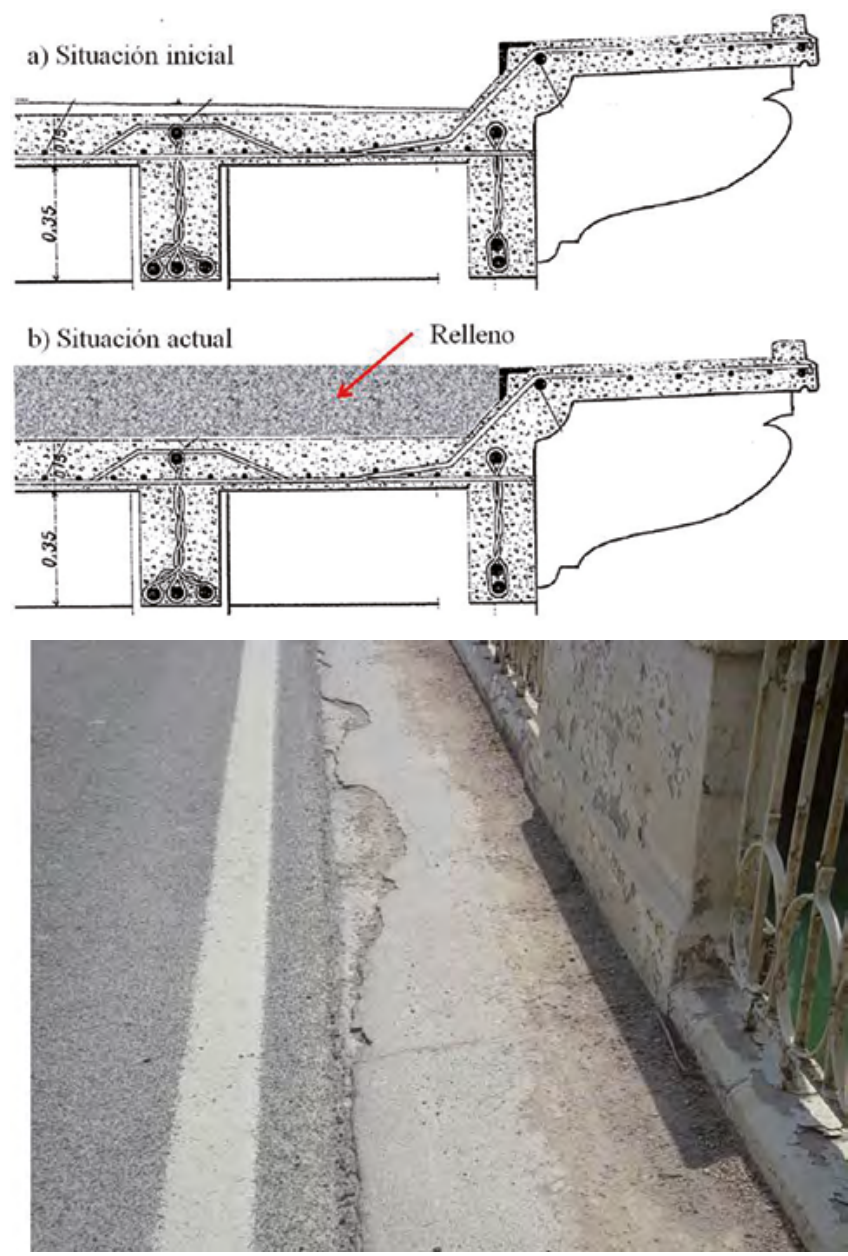

Figura 14. Sección transversal del puente de Liédena, antes de la reparación (figura de los autores), en la que se aprecia el espacio de facto habilitado indebidamente para el cruce de vehículos. 

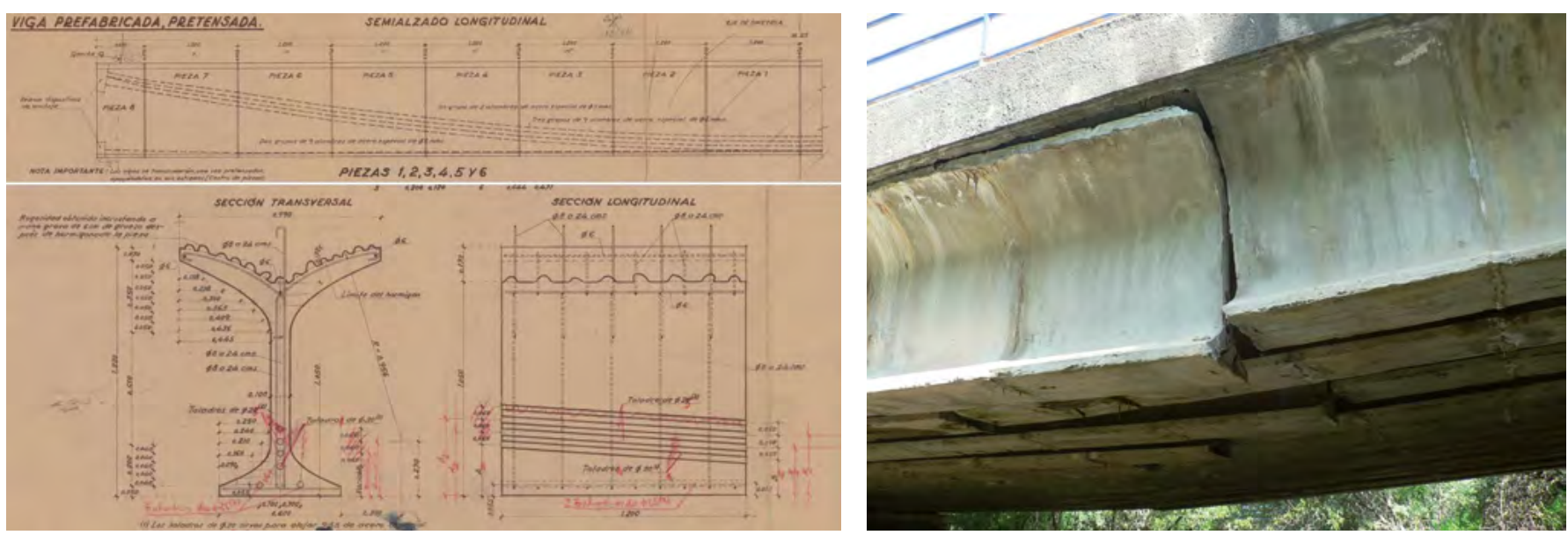

Figura 15. Ejemplo de puente pretensado anterior a 1970 (el mismo que el de la figura 9). A la izquierda, planos del proyecto que especifican la inyección, en la práctica imposible. A la derecha, configuración previa al colapso al desconectarse las dovelas [17].

7.

\section{PERTENENCIA A UN GRUPO DE RIESGO POR RAZONES TECNOLÓGICAS}

Esta calificación es fruto de la vivencia de los autores en casi todos los casos que se citan. Naturalmente, cuando se proyectaron y construyeron estos puentes haciendo uso de recursos tecnológicos del momento, no siempre suficientemente experimentados, no se era consciente de la evolución futura de lo implantado. Al contrario, se tendió a sobrevalorar las prestaciones de lo nuevo y a infravalorar su evolución o incluso ciertas contraindicaciones, que, por supuesto, no eran conocidas. Eso es consustancial con el progreso, como lo es, inteligentemente, detectar las ventajas y los inconvenientes, tomando las medidas correspondientes para corregirlos en aplicaciones futuras o para tenerlos seriamente en cuenta en las situaciones existentes que ya no es posible eludir. Ese es también, modestamente, el propósito de este artículo. Algunos de estos casos o grupos de riesgo son los siguientes:

\section{Puentes pretensados anteriores a 1970, aproximadamente}

Comportan mayor probabilidad de fallo porque no se habían depurado aún las técnicas de inyección, los aceros eran más sensibles a la corrosión que los más modernos y, además, el tiempo transcurrido se ha acercado al final de su vida útil, habiéndose podido producir pérdidas significativas de durabilidad (figura 15), además de haberse dado otras concomitancias adversas. Cifrar en un año concreto esa frontera es discutible. ¿Empieza la Edad Moderna el día en que cae Constantinopla?; ¿al inventarse la imprenta?; ¿cuándo se toma Granada o se descubre América? Es una mera referencia. Cabe asignar $p=3$ y consecuencias de fallo según la tabla 1. En la referencia [17] se presenta un ejemplo significativo de esto. Aun a riesgo de resultar reiterativos, cabe destacar la importancia de conservar un registro histórico individualizado o colectivo. En España se cuenta con la colección de Hormigón Pretensado. Realizaciones Españolas, iniciada en 1970 [18], que hace memoria colectiva de las construcciones españolas en pretensado, particularmente en puentes, cuyas fichas deberían ser objeto de consulta por parte de las administraciones responsables.

\section{Puentes atirantados con tirantes inyectados o de pretensado exterior}

Si bien se trata de una tecnología superada desde mediada la década de 1990, aproximadamente, los tirantes pueden deparar alguna sorpresa como la que se muestra en la figura 16, al producirse vacíos en la inyección que, aun en ausencia de cloruros y de carbonatación, pueden dar lugar a diferencias de contenido de $\mathrm{pH}$ y a corrosión anódica. Cabe asignar $p=2 \mathrm{y}$ consecuencias de fallo según la tabla 1.

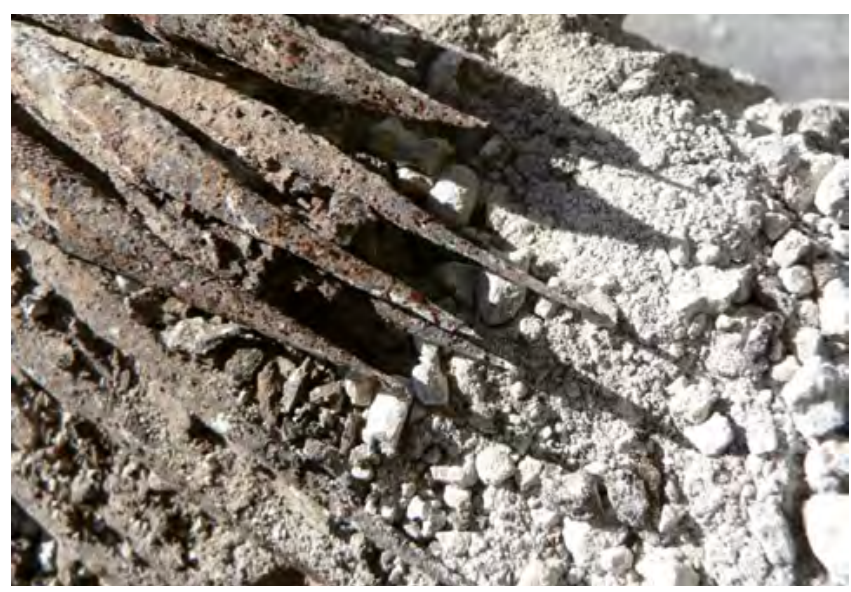

Figura 16. Tirante roto en el puente Fernando Reig en Alcoy (julio de 2016). Corrosión anódica. Foto de los autores. Se procedió a la sustitución del 100\% de los tirantes.

\section{Puentes con tirantes en presencia de materia orgánica}

Es el caso de puentes con tirantes de retenida que, aun galvanizados, estén en presencia de fosfatos y amonio, pues pueden desarrollarse mecanismos de rotura por corrosión bajo tensión, como se muestra en la figura 17. Cabe asignar $p=3$ y consecuencias de fallo como en la tabla 1. La asignación de tal valor de categoría de probabilidad tiene que ver con la casi inevitable presencia de materia orgánica en tales anclajes. Se dice "casi" porque ahora, que se sabe, cabe organizar un mantenimiento específicamente orientado a eliminar o paliar la causa de los problemas (materia orgánica) y a plantear algún sistema de monitorización. 


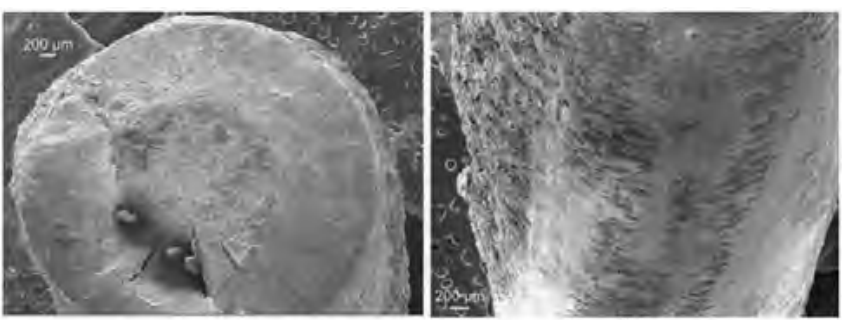

Figura 9.- Tipolog âr de rofura duictil del alambre central del cordón collapsado de la pila P-13.

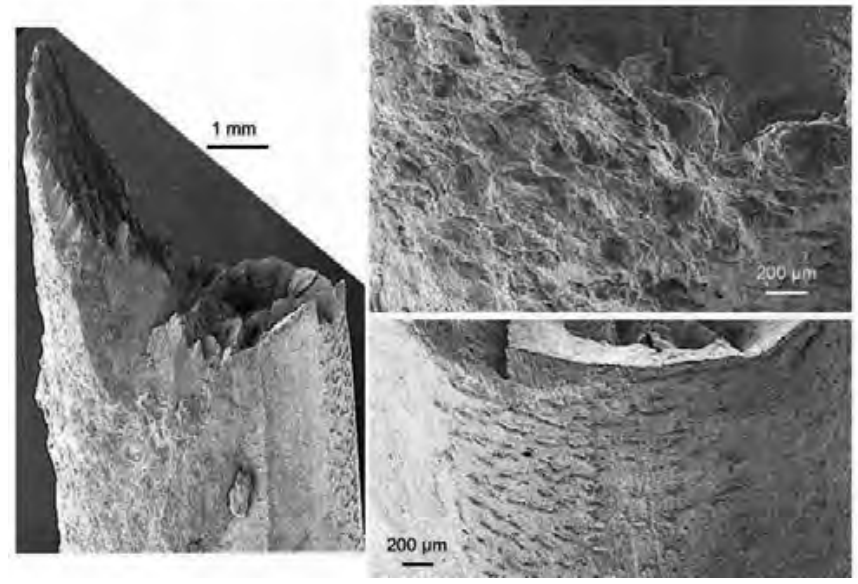

Figura 17. Tirante roto por corrosión bajo tensión en un puente con retenidas galvanizadas pero en presencia de restos orgánicos. Foto cortesía del Laboratorio de Ciencia de Materiales de la ETSICCP-UPM en trabajo realizado por encargo de los autores.

\section{Puentes metálicos}

Suelen presentar, en ciertas tipologías, detalles con más probabilidad de fallo y ser de más difícil inspección que otros tipos de puentes (figura 18). Simplificadamente, cabe asignar $p=2 \mathrm{y}$ consecuencias de fallo como en la tabla 1 .

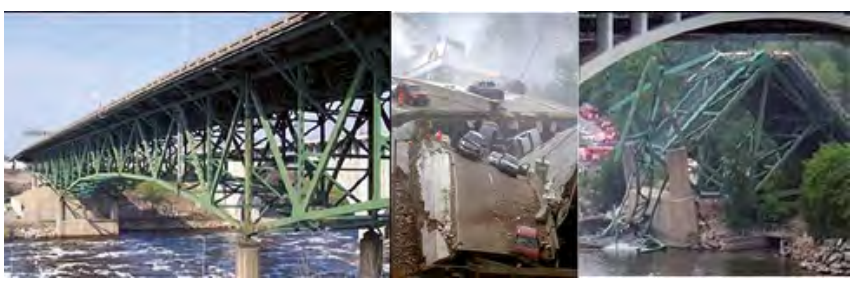

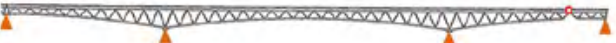

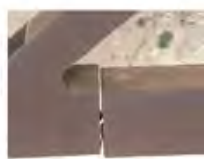

Figura 18. Ejemplos de puentes metálicos con fallos de difícil detección. Arriba, puente de Minneapolis (1 de agosto de 2007). Abajo, fallo por fatiga de soldadura en un puente de la A-3 (foto de los autores, 2013)

\section{Artesas o cajones únicos (no varias unidades en el mismo tablero)}

Son piezas sensibles, con probabilidad mayor de sufrir roturas a torsión y cortante por sobre-compresión del alma (figura 19, en cuyo esquema se indica cómo se superponen las compresiones del alma debidas al cortante con las debidas al momento torsor, habiéndose dibujado solo la mitad de la analogía de Rausch para mayor claridad), especialmente si experimentan distorsiones angulares que den lugar a torsiones que se acoplan con cortante, como sucede si hay descensos diferenciales en sentido transversal o si se pierde un aparato de apoyo. Cabe asignar $p=2$ y consecuencias de fallo como en la tabla 1 .

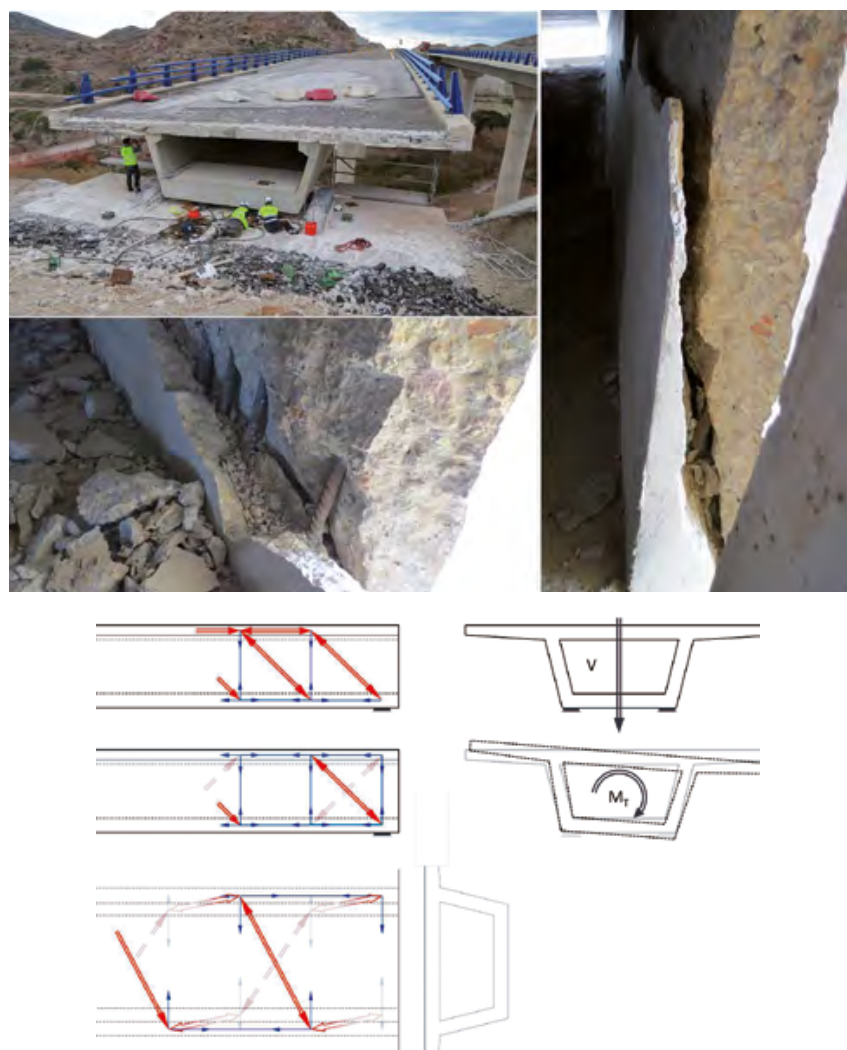

Figura 19. Ejemplo de rotura de alma por compresión excesiva debida a descenso diferencial en la AP-7. Fotos y esquema de los autores.

\section{Puentes con apoyos a media madera}

Este recurso, profusamente utilizado, está proscrito desde hace años y ha de ser objeto de vigilancia particular. Se pueden distinguir diferentes configuraciones, con creciente probabilidad de fallo:

\section{En centro de vano}

Se da en algunos puentes, construidos por voladizos sucesivos en los años 60 del s. XX, en que se disponía rótula en el encuentro de los voladizos. Es el caso del puente de la figura 20, en el que se produjo una rotura por fatiga de las barras de cosido. Cabe asignar $p=2$ y consecuencias de fallo como en la tabla 1.
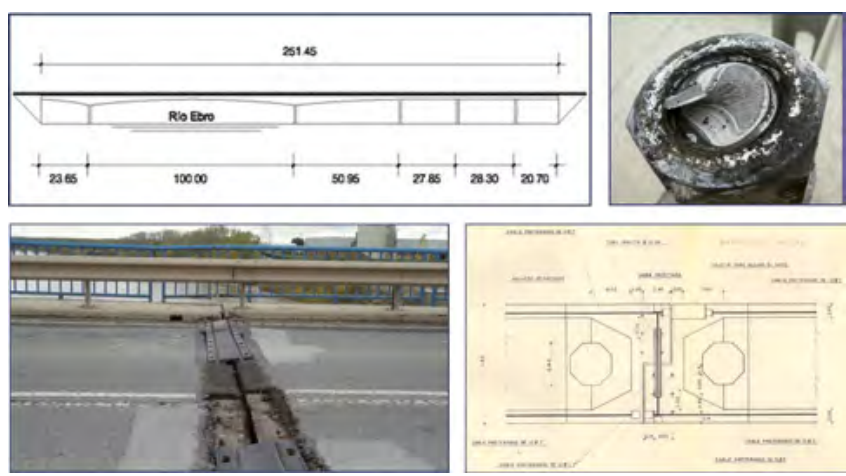

Figura 20. Ejemplo de apoyo a media madera con barras pasantes. Puente de Castejón (Navarra). Fotos de los autores. 


\section{Sobre pila o estribo}

Es la situación más frecuente en muchos pasos superiores, a menudo prefabricados, sobre autopista o autovía. Cabe asignar $p=2$ y consecuencias de fallo como en la tabla 1 .

\section{En vano (Gerber)}

La probabilidad de fallo es mayor en estos apoyos intermedios en vano, como se ha podido comprobar desgraciadamente (figura 21). Cabe asignar $p=3$ y consecuencias de fallo como en la tabla 1. El problema está vinculado, en estos casos, al deterioro de la armadura de las zonas de apoyo a media madera (que no siempre obedece al detalle correcto) y a la mayor probabilidad de entrada de agua con agresivos en la junta que existe en la calzada. De las dos partes de la media madera, es la inferior la que resulta siempre crítica, como se ve en la figura 21.

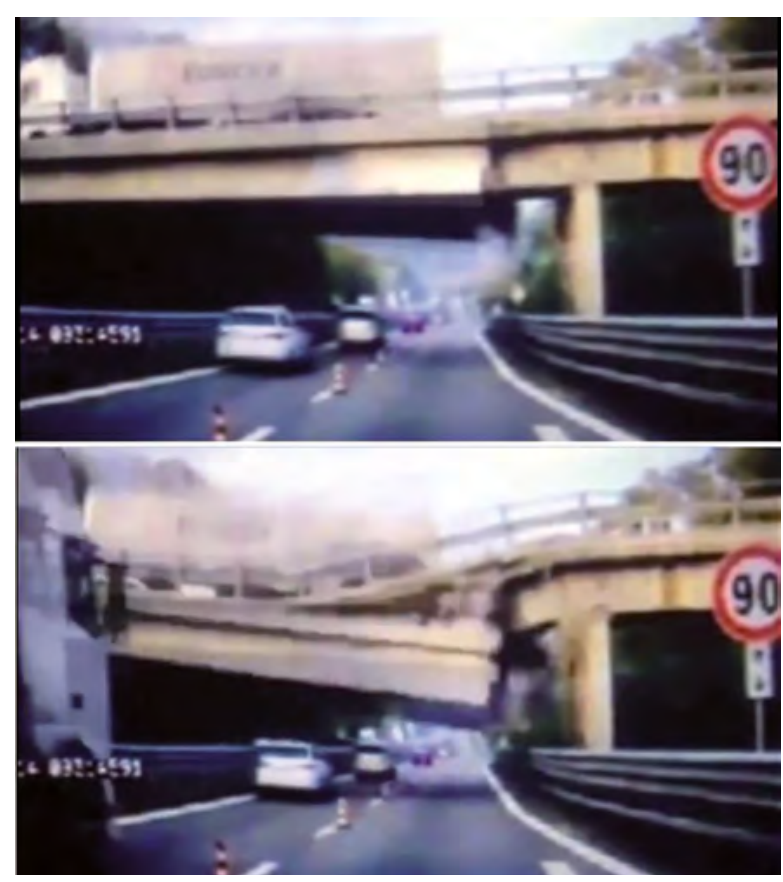

Figura 21. Ejemplo de colapso de un apoyo intermedio a media madera, en dos fotogramas (tomado de [19]).

\section{Armaduras que atraviesan hormigones diferentes}

Se trata de una situación que difícilmente pudieron considerar como de riesgo los proyectistas y constructores de puentes en que las armaduras atraviesan hormigones de diferente naturaleza (generalmente hormigones in situ y prefabricados). Sin embargo, a igualdad de condiciones de exposición, se pueden generar procesos de corrosión anódica, muy particularmente en la interfaz de ambos hormigones (figura 22), especialmente concentrada en las armaduras de acero estirado en frío, más sensible, como es sabido, a la corrosión que los aceros de dureza natural. Cabe asignar $p=3$ y consecuencias de fallo como en la tabla 1 .

\section{Esfuerzo rasante entre hormigones dispuestos en momentos diferentes}

Identificado como estado límite desde hace ya tiempo [20], el de rasante no se presenta con frecuencia, por fortuna. Se trata, como es bien sabido, de asegurar que los esfuerzos internos (tracciones y compresiones), o sus variaciones, pasen a la sec-

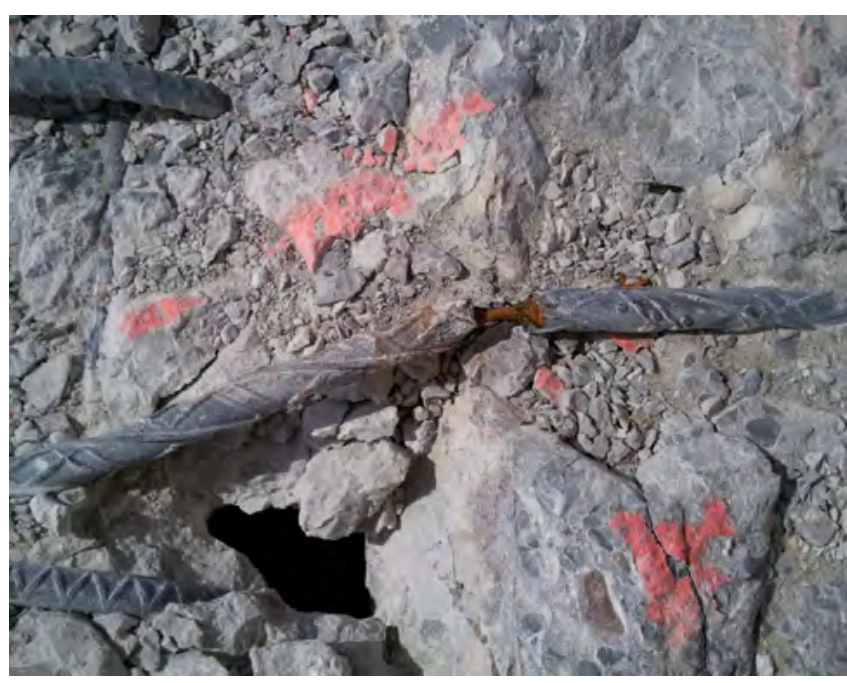

Figura 22. Armaduras corroídas en la interfaz hormigón prefabricado - hormigón in situ. Fotos cortesía de AUDENASA, concesionario que puede ponerse como modelo de actuación en la gestión del mantenimiento ordinario y especializado.

ción completa, considerada mecánicamente como monolítica, a través de la superficie entre dos hormigones dispuestos en instantes distintos. Puesto que es imposible asegurar una eficacia en la interfaz equivalente a la de un hormigón monolítico [21], es preciso disponer armadura de cosido para que movilice los mecanismos de corte-fricción (si está anclada) y de pasador. Además, se ha observado en la reglamentación una tendencia regresiva con relación a la relajación, equivocada, que se planteó a finales de la década de 1990, volviendo a plantear esfuerzos rasantes más bien proporcionales al esfuerzo cortante (rasante mal llamado "elástico" en ELU) y parámetros más exigentes para tener en cuenta la rugosidad y la cohesión.

Un riesgo tecnológico añadido que los autores han detectado es el asociado a la disposición de resina epoxi en la junta. Si bien esos productos han demostrado ser muy solventes, se han detectado deficiencias en la ejecución, tanto por la presencia de suciedad o de agua (con resinas incompatibles con la humedad o el agua líquida) como por no respetarse los tiempos de polimerización. La figura 23 muestra el caso, vivido por los autores en 2020, en una actuación de emergencia, de un recrecido vertido sobre una losa de puente. Si bien la resina impregnó claramente el hormigón del sustrato, polimerizó antes del vertido del hormigón del recrecido, generándose un plano de deslizamiento que, sin armadura, convirtió al recrecido, que alojaba la mayor parte de la armadura de flexión transversal por error previo de ejecución, en una pieza adicional meramente superpuesta que manifestó, afortunadamente, los síntomas (por fallo en el pavimento) de la no adherencia. Esa señal, típicamente achacable a un fallo en la impermeabilización y a la no adherencia entre pavimento y losa, advirtió, tras mucha reflexión, que se habría tratado de un fallo frágil de graves consecuencias.

Consiguientemente, se consignaría $p=3$ para los casos en que se haya dispuesto resina y no haya armadura de cosido, $p=2$ en los que, haya o no resina, haya armadura de cosido, $p=1$ si se ha ejecutado un cosido, no se ha dispuesto resina y se ha dispuesto rugosidad y ejecución limpia y, finalmente, $\lambda=0 \mathrm{si}$ no hay junta. Para $c$ se tomarán los valores de la tabla 1 . 


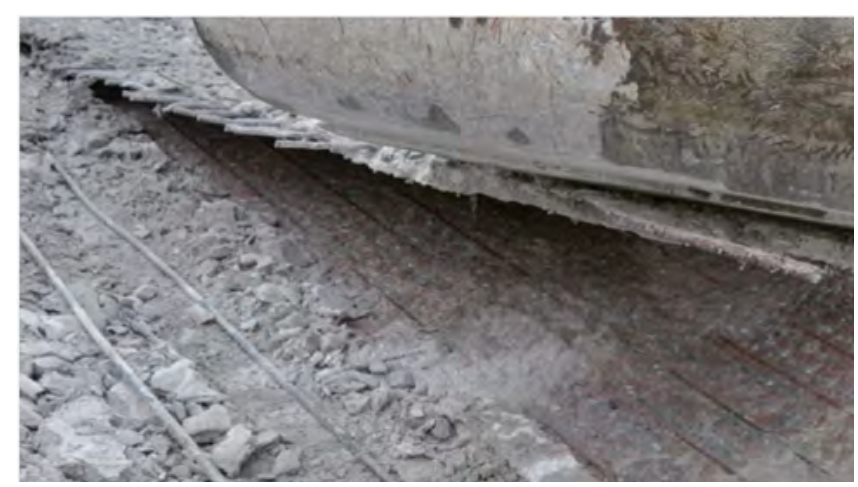

Figura 23. Recrecido desconectado en la losa superior de un puente. No había armadura de conexión, por error de proyecto, pero lo peor era que la resina en que se confió, que había impregnado en el sustrato, polimerizó antes de verter el hormigón del recrecido, propiciando el deslizamiento.

\section{Tableros de vigas $T$ o artesa con hormigones con muchos adi- tivos}

Se trata de un riesgo tecnológico asociado al uso de aditivos que, con indiscutibles ventajas constructivas, pueden llevar aparejados inconvenientes como la producción de una "nata" en la parte superior de la tongada que afecte a la capacidad a cortante (o rasante) al perderse el monolitismo del alma porque se producen de facto juntas frías de carácter cuasi-horizontal, con desplazamiento relativo. Puede ser el caso de estructuras construidas a partir de 2000 (figura 24), aproximadamente. Cabe asignar $p=2$ y consecuencias de fallo como en la tabla 1 .
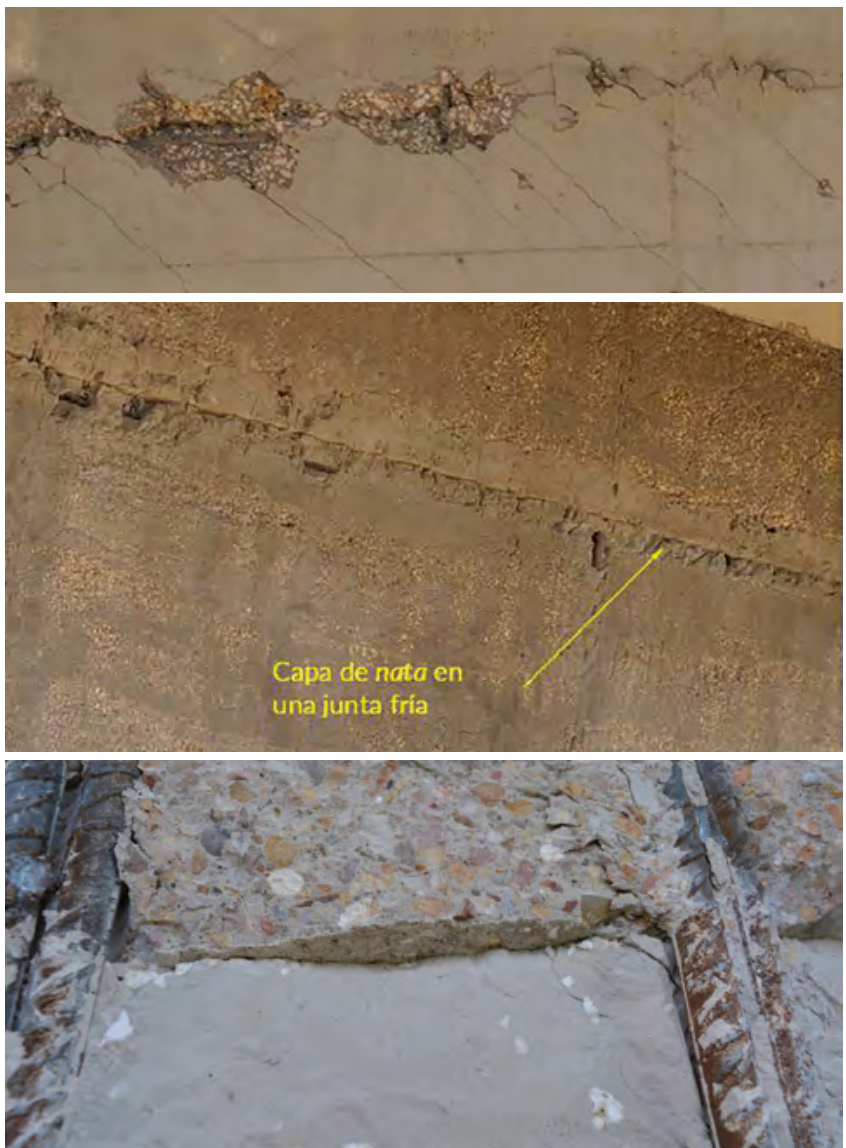

Figura 24. Juntas frias no deliberadas en el alma de una artesa por la formación de una nata. Fotos FHECOR.
Cimentaciones profundas de puentes de piedra o ladrillo

Se trata, como se anticipó al tratar de la socavación, del riesgo asociado a los menores conocimientos de la Mecánica de Suelos y a los más deficientes métodos constructivos de aquellos proyectistas y constructores en comparación con los disponibles desde mediados del s. XX, lo que otorga aún mayor mérito a aquellos bravos ingenieros. Como se ha explicado ya [11, 22 y 23], el talón de Aquiles de los nobles puentes de piedra o ladrillo estaba precisamente en sus cimentaciones, especialmente si no eran directas (roca o terrenos no susceptibles a la socavación). Los efectos se manifiestan en descensos y en giros que, en el caso de puentes de piedra o ladrillo (figura 25), se traducen en desórdenes en las bóvedas con un rápido y progresivo descenso del nivel de seguridad. Cabe asignar $p=3 \mathrm{y}$ consecuencias de fallo como en la tabla 1.
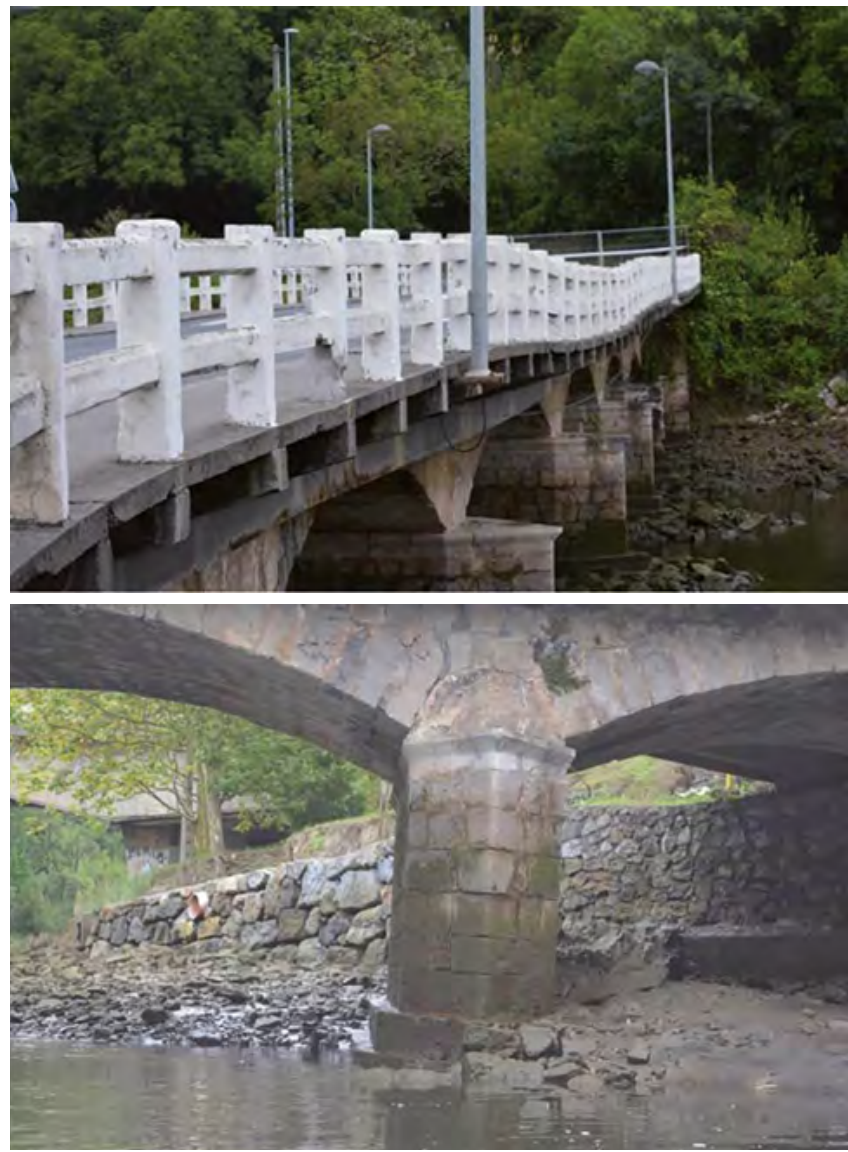

Figura 25. Descensos y giros en pila como consecuencia del deterioro progresivo de las cimentaciones profundas (pilotes) del puente de Astiñene (S. Sebastián). Fotos de los autores (2017).

Merece la pena añadir que, hasta donde los autores saben, es poco conocido el hecho de que las pilas que descienden ven aumentar la reacción vertical que gravita sobre ellas y eso, obviamente, compromete aún más su estabilidad, pues un incremento de carga suele traer consigo un aumento de los efectos provocados por esta. En la figura 26 se esquematiza el efecto engañoso que la costumbre puede generar en el ingeniero estructural, que tiende a considerar universal el hecho de que, en sistemas rígidos como las vigas continuas, el descenso de uno de sus apoyos se traduce en una relajación de la reacción. Eso es, en efecto, cierto en vigas, pero opuesto en el caso de bóvedas. Puede verse que a medida que sube un apoyo (desciende 


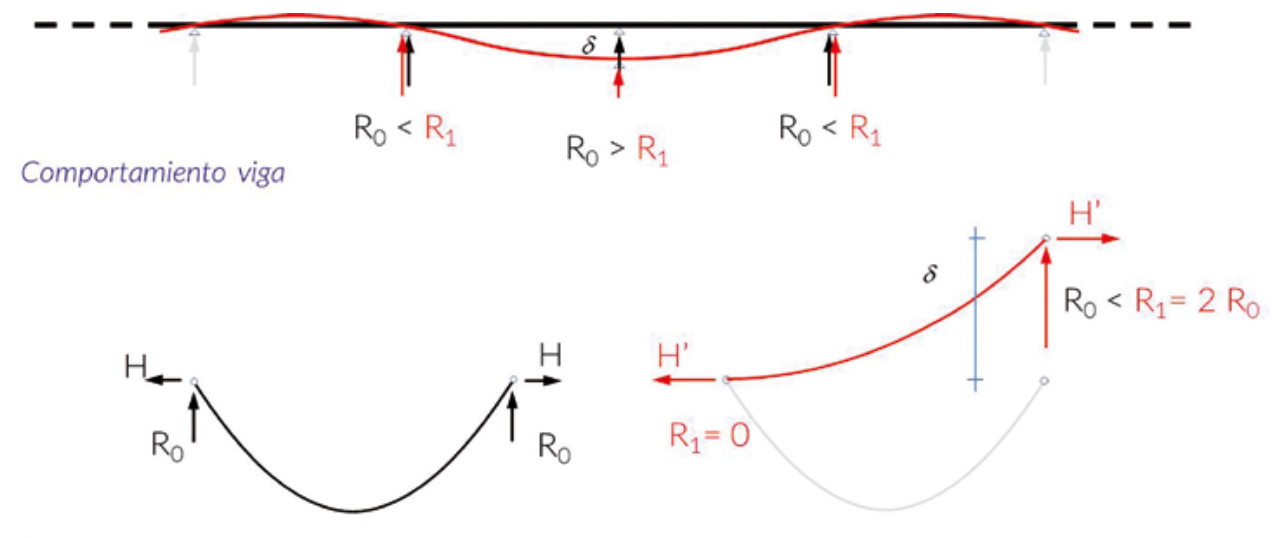

Comportamiento funicular

Figura 26. Contraste del efecto estructural generado por el descenso $\delta$ de un apoyo en una viga continua y en un arco o bóveda, respectivamente. Figura de los autores.

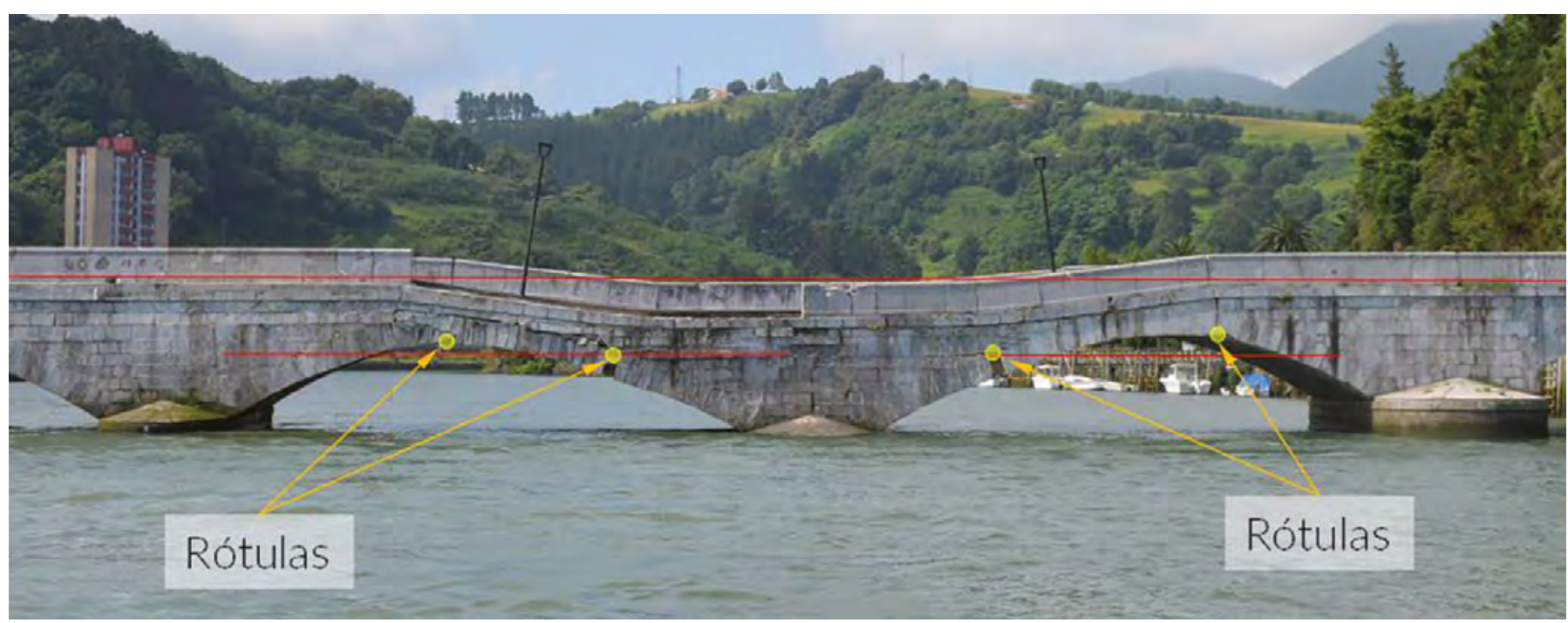

Figura 27. Puente de Deba tras el colapso parcial de la pila 2. Foto de los autores.

en la expresión antifunicular) la reacción aumenta hasta ser el $100 \%$ de la carga total actuante cuando la línea de presiones se hace horizontal en el apoyo que no se mueve. También crece la reacción horizontal, desequilibrante.

\section{Ataque de xilófagos a las cimentaciones profundas en puen- tes situados en estuarios}

Los autores han vivido la experiencia del colapso parcial del puente de la ría de Deba (Guipúzcoa, 2018, figura 27). Aunque los síntomas externos y las consecuencias estructurales son semejantes a los de la socavación, sus causas son muy diferentes. Se da solamente en puentes situados en estuarios, es decir, cuando el agua salobre libre (no en fango o en arenas) constituye el hábitat propicio del Teredo Navalis o broma, conocido de los marinos de la época dorada de los buques de madera, que protegían sus cascos con chapas de cobre. También lo sabía el ingeniero restaurador del puente de Deba hacia 1890, que dejó constancia de ese riesgo que ha pasado inadvertido en lo sucesivo. Se trata de un molusco lamelibranquio (no es un gusano) emparentado con las más apetitosas navajas. Se alimenta de la celulosa que procesa al ingerir la madera, formando túneles en la madera que son indetectables desde el exterior. A medida que pasa el tiempo y la broma hace su trabajo, se va perdiendo sección resistente (figura 28) y sobreviene el colapso. Como se indica en la figura 26, se estima que el descenso de la pila provocó un incremento del 20\% en el esfuerzo axil de la misma.

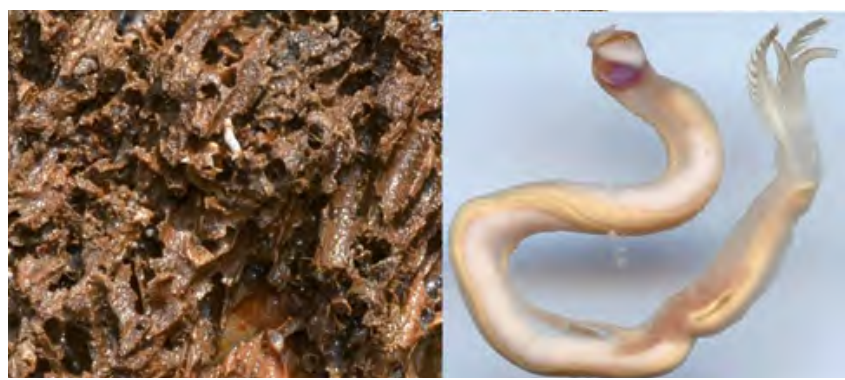

Figura 28. Aspecto del Teredo Navalis o broma y de sus efectos en la madera de los pilotes del puente de Deba (foto de los autores). 
Salvo que se tenga constancia de recalces posteriores libres de madera (o no se haya producido el lavado del material bajo el encepado), cosa de muy difícil detección, los puentes en estuarios con cimentaciones profundas a base de pilotes de madera merecen una categoría de probabilidad $p=3$ y consecuencias de fallo como en la tabla 1.

\section{Tímpanos de los puentes de piedra o ladrillo}

Planteados originariamente como muros de contención de los rellenos rígidos (durante la construcción) y de los granulares presentes en el trasdós de las bóvedas de estos puentes, el deterioro de dichos rellenos como consecuencia de la lixiviación del calicanto, de forma que este deja de resistir sin empujar y pasa a no resistir y empujar, unido a la aportación de agua, puede dar lugar a una rotura frágil, sin previo aviso, con consecuencias potenciales graves (figura 29). A falta de mayor información, cabe considerar $p=3$ y consecuencias como las de la tabla 1.

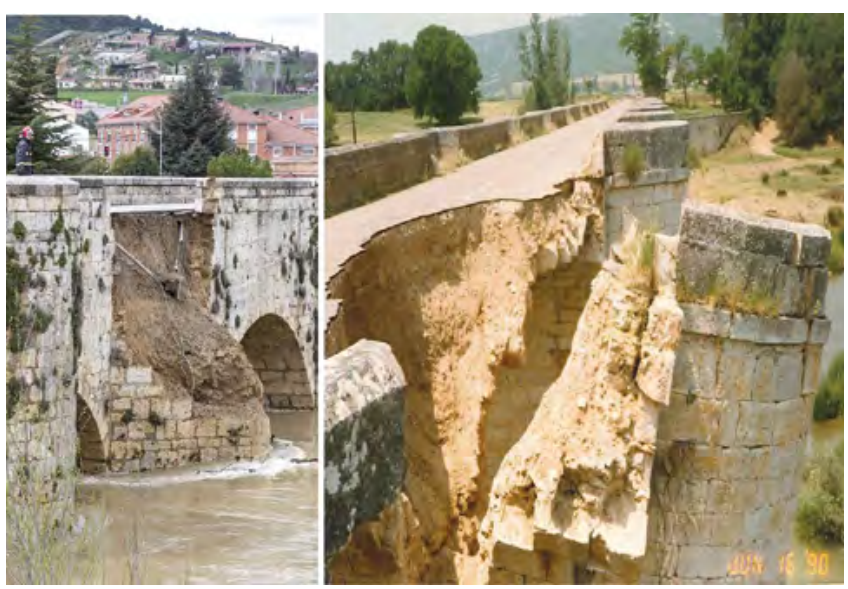

Figura 29. Ejemplos de rotura de tímpanos de puentes de piedra (a la izquierda, foto de prensa; a la derecha, cortesía de RODIO).

\section{Puentes de bóvedas rebajadas de ladrillo}

Los autores han constatado la mayor probabilidad de fallo de estos puentes, al cabo de muchos años, por fluencia diferencial y fallo por rasante (figura 30), en efectos acoplados. Los autores solo han detectado dos casos significativos, con bóvedas de directriz carpanel. Cabe asignar $p=2$ y consecuencias de fallo como en la tabla 1 .

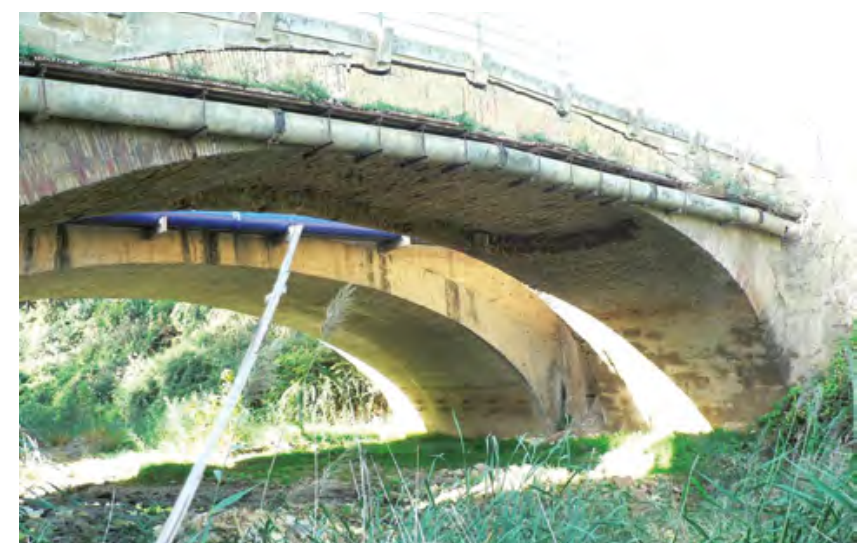

Figura 30. Ejemplo de colapso de parcial de puente de fábrica con bóveda rebajada de ladrillo. Puente de Ejea de los Caballeros. Foto de los autores.

\section{8.}

\section{CLASE DE EXPOSICIÓN}

Como es natural, la clase de exposición es un factor acelerador de los deterioros y, en consecuencia, de la probabilidad de fallo (figura 31). Con carácter general, si hay plan de mantenimiento que se lleva a cabo, sea cual sea el tipo de exposición ambiental, o hay constancia de estar impermeabilizado o de no tener juntas (puente integral) se podría considerar $p=1$. Si no hay constancia de existir impermeabilización y no se emplean fundentes ni hay riesgo de ataque por sulfatos o árido-álcali, $p=2$. Si se utilizan sales fundentes, no hay constancia de impermeabilización o no se puede excluir el riesgo de ataque por sulfatos o árido-álcali, $p=3$.

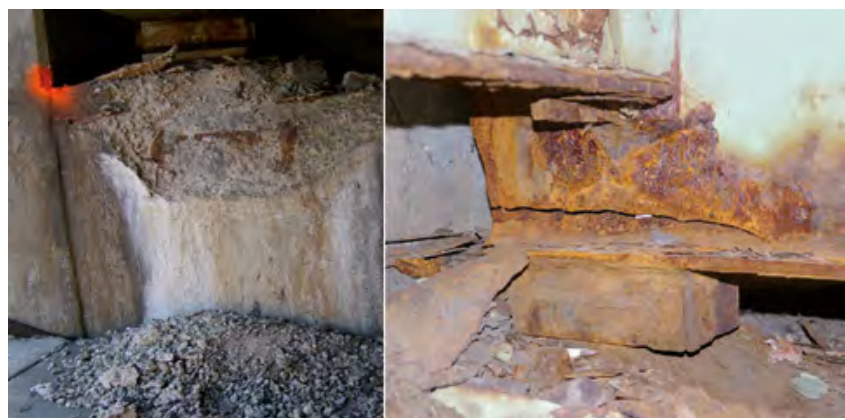

Figura 31. Deterioros en el hormigón y en el acero en una clase de exposición adversa (en este último caso con una rotura por tracción del alma debida al deterioro del hormigón bajo el aparato de apoyo) [24].

9.

\section{ROBUSTEZ}

Se trata de una cualidad de gran importancia pero cuyo conocimiento y comprensión no están todo lo extendidos que debieran. Una estructura es robusta cuando el fallo de un simple componente no genera consecuencias desproporcionadas y extendidas al resto de la estructura. Se trata de una cualidad que incide en las clases de consecuencia más allá de lo contemplado en la tabla 1, apuntando a $c=3$ en casos como los de las figuras 32 a 34. En el caso de la figura 32, la corrosión generalizada de los tendones provocó, aparentemente sin previo aviso, la ruina inevitable de toda la obra. La imagen de la figura 33 corresponde al conocido hundimiento del puente Polcevera. El grandísimo ingeniero Morandi no sabía (ni nadie entonces) que la extraordinaria dependencia de la integridad de los componentes de su ingenioso sistema estático podría desembocar, 51 años después de la inauguración, en un fallo tan catastrófico, cosa que no sucedió en puentes como el de Alcoy, con muchos tirantes que, en general, pueden ser capaces de asumir el papel de alguno que falle. Tampoco era consciente nadie, o eso parece, de los efectos inexorables de la corrosión.

Cabe mencionar, finalmente, el caso del puente de Albano Magra, hundido el 8 de abril de 2020. Considerado "seguro" tras una inspección realizada unos meses antes del colapso, el puente falló en todos sus vanos de manera progresiva sin que mediara causa directa aparente (no se trató de una socavación, ni pasaban transportes pesados; en pleno confinamiento por la pandemia, solo dos furgonetas). Cabe pensar, y esto es cosecha 


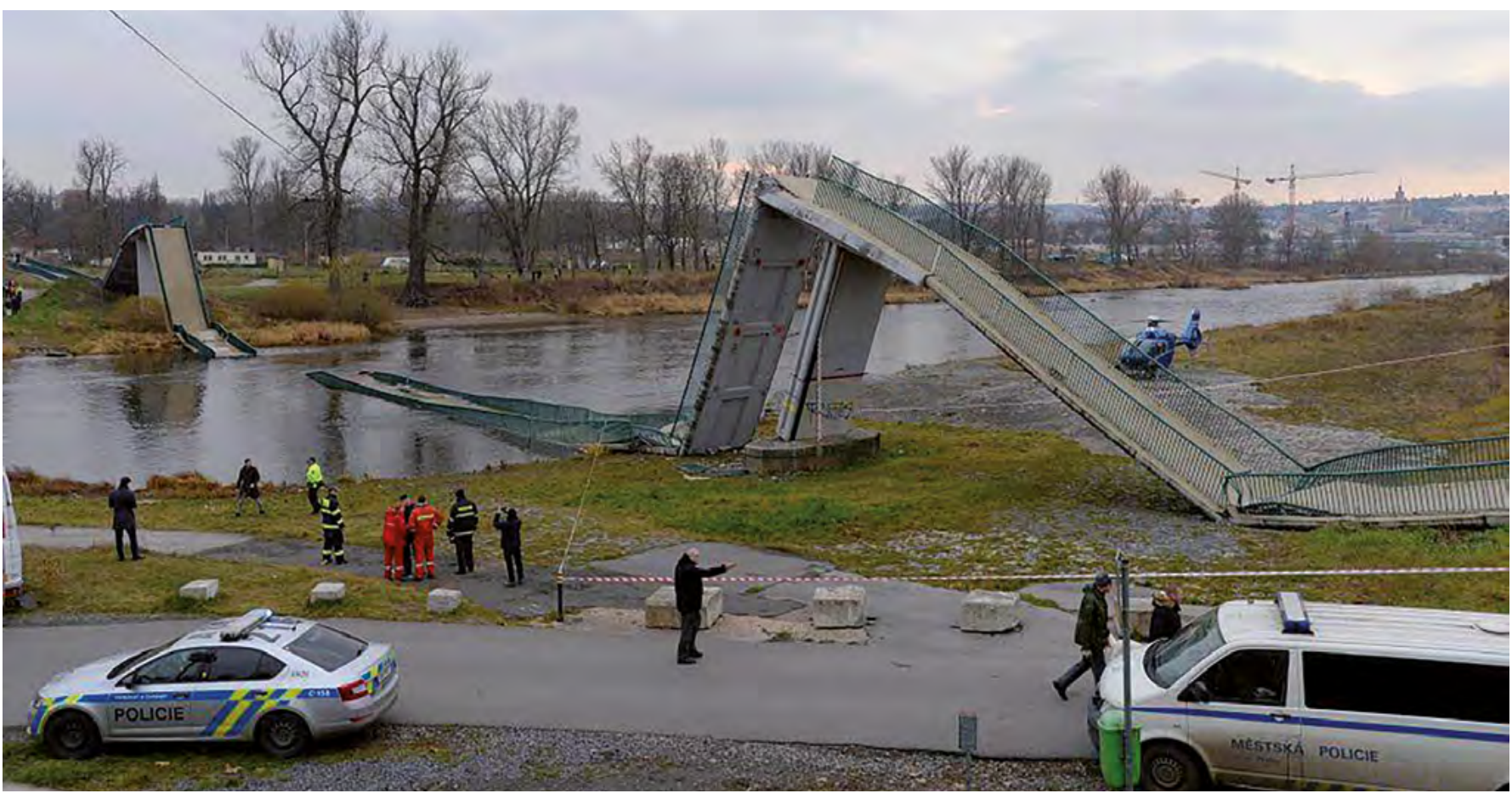

Figura 32. Banda tesa de una pasarela. Troja, cerca de Praga, República Checa, 2 de diciembre de 2017.

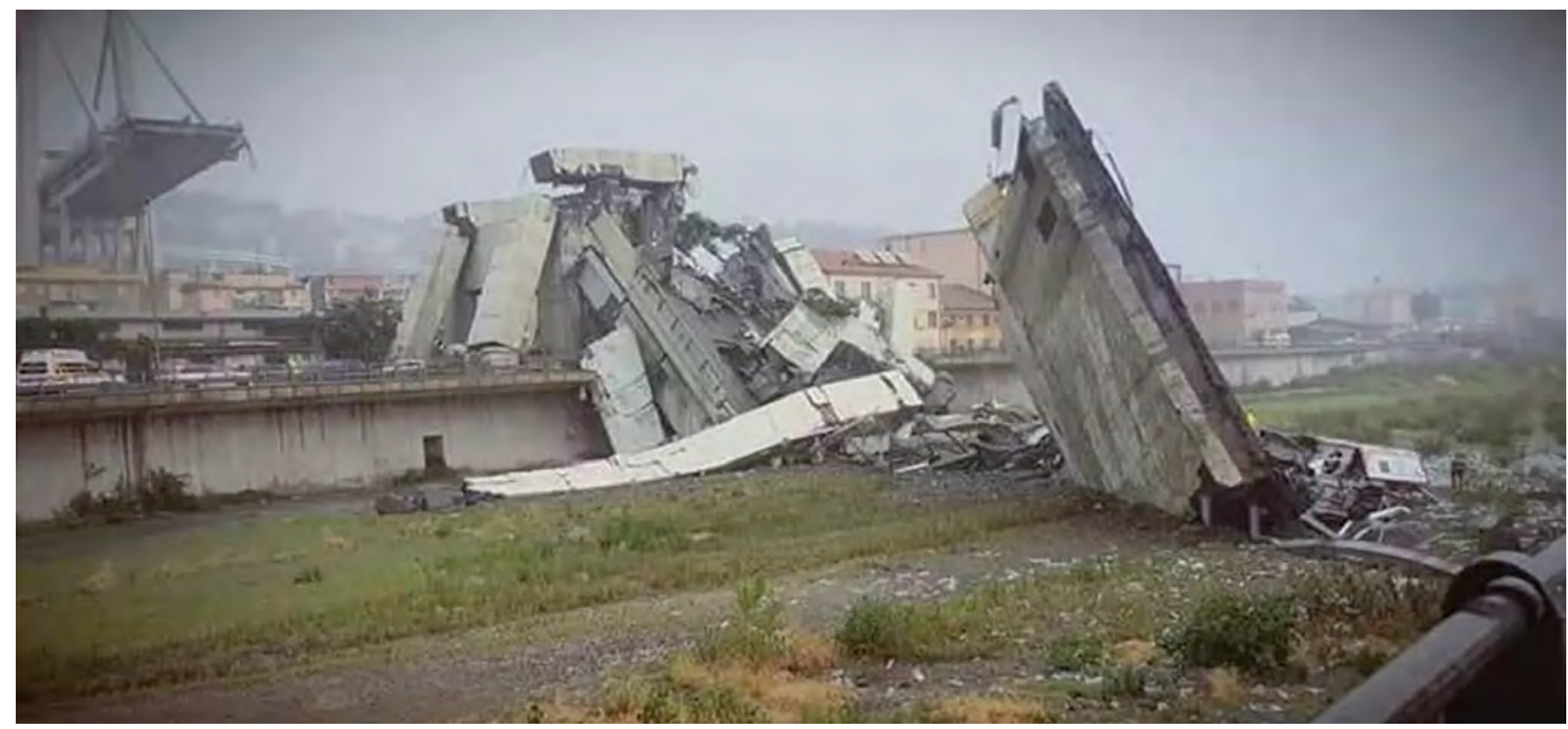

Figura 33. Colapso del puente Polcevera, Génova, Italia, 2018 [25].

de los autores de este artículo, que se produjera un fallo en la pila, construida con un cajón indio, y que la lixiviación del hormigón (similar a la que se muestra en la figura 35, correspondiente a otro puente) ya desprotegido por el cajón primitivo, muy dañado, hubiese producido un descenso súbito de una de las pilas (en cauce), con una cinemática como la que se expone en la figura 36. El proceso se habría iniciado con un descenso de la única pila en cauce que acabaría por arrastrar a los dos arcos concurrentes. La pila adyacente a la colapsada habría girado al no ser capaz de resistir el empuje desequilibrado y propiciaría el colapso de esa tercera bóveda, repitiéndose el proceso sucesivamente en las siguientes pilas y arcos
10.

\section{ASPECTOS PATRIMONIALES}

Como se señaló al comenzar, entre las consecuencias, no recogidas en la tabla 1, están potenciales pérdidas del patrimonio construido por razones que se explican en [2], entre otros documentos. Como allí expone el primero de los autores del presente artículo, del cotidiano y aparentemente gratuito don que es el patrimonio construido, se puede pasar, en un tris (o poco a poco, con grandes dosis de desidia), a la pérdida de esa herencia, en sentido lato. Los casos recientes de colapsos de puentes son ejemplos de la acumulación súbita de reconocimientos y lamentos tardios por lo perdido. 


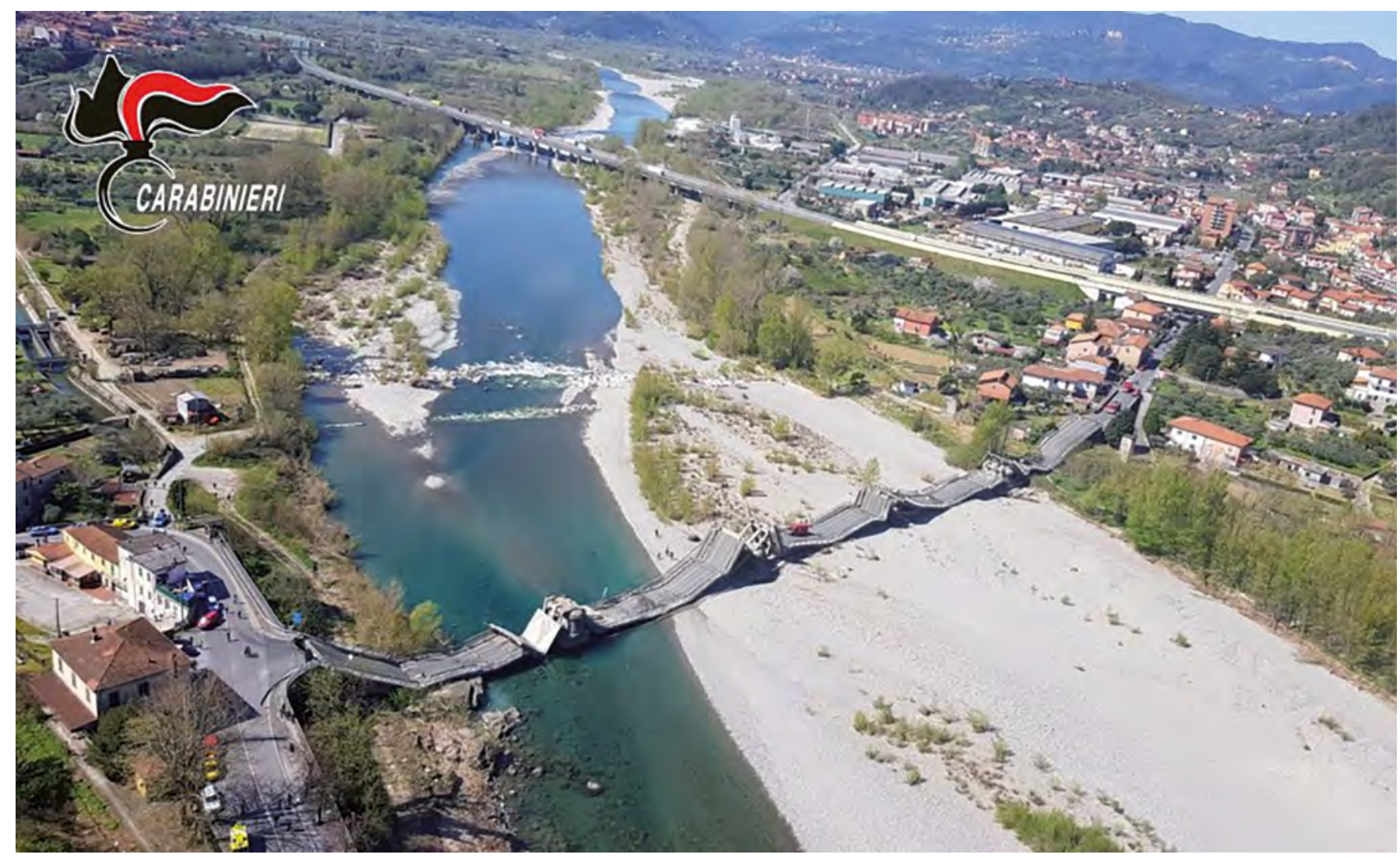

Figura 34. Colapso del puente de Albano Magra, 8 de abril de 2020. Foto difundida a los medios de comunicación.

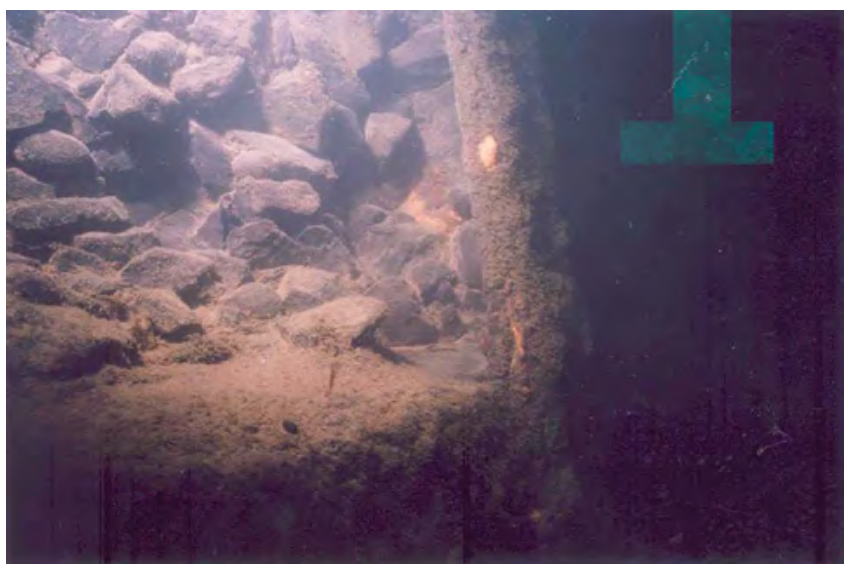

Figura 35. Hormigón lixiviado (ligante disuelto) y degradado en el puente de San Clodio, sobre el Sil. Trabajo de los autores en 2004.

Por "valor patrimonial" no se entiende, en este apartado, el de reposición, sino el que resulta de valorar, según [2], aspectos como el de conservación, el emotivo y social, el estético, paisajístico y medioambiental, el histórico, el técnico y estructural y, por supuesto, el de uso. A igualdad de probabilidad de fallo, las consecuencias no son las mismas, desde el punto de vista patrimonial, en un paso superior tipo y repetitivo que en un paso superior cualquiera de D. Carlos Fernández Casado (el de La Navata, p.e.) en la A-6, o en el puente del Arzobispo, o en el viaducto de Ormáiztegui que pintara Regoyos, o en el puente de Zamora que dibujara con versos Blas de Otero, o en el Paso Honroso que fuera escenario del lance de Suero de Quiñones en Hospital de Órbigo, o las juntas de rodadura que tienen las bóvedas de piedra de la aparentemente modesta estructura en la desembocadura del río Xallas, o el primer puente en el que se utilizó hormigón de cemento blanco (paso superior de Juan Bravo, en Madrid), por poner solo unos ejemplos.

\section{1.}

\section{CONSIDERACIONES FINALES}

Los autores mantienen la idea de que la gestión de un patrimonio de puentes, que pasa por los conocidos escalones de inventario y sucesivas inspecciones principales (acompañadas deseablemente entre medias por las rutinarias), debe incluir el estudio de los riesgos, siquiera a un nivel como el que se propone en este artículo, con un enfoque orientado a la obtención de indicadores. Eso permitirá a los administradores jerarquizar, con mayor fundamento y un enfoque diferente y reforzado, las frecuencias de inspección y las necesidades de acometer inspecciones especiales, antesala frecuente de los proyectos y obras de rehabilitación. Obsérvese que la nota $r$ (de riesgo, figura 3) depende inicialmente de la naturaleza y las circunstancias del puente, no de su estado, al menos directamente. Obviamente, la probabilidad p de fallo crece al crecer el deterioro.

La experiencia demuestra que algunas causas de los colapsos de puentes están relacionadas con los aspectos identificados sintéticamente en estas líneas y que cada uno de ellos requiere estudios más profundos e interdisciplinares. También enseña que el día a día de la praxis de la Ingeniería de Conservación 

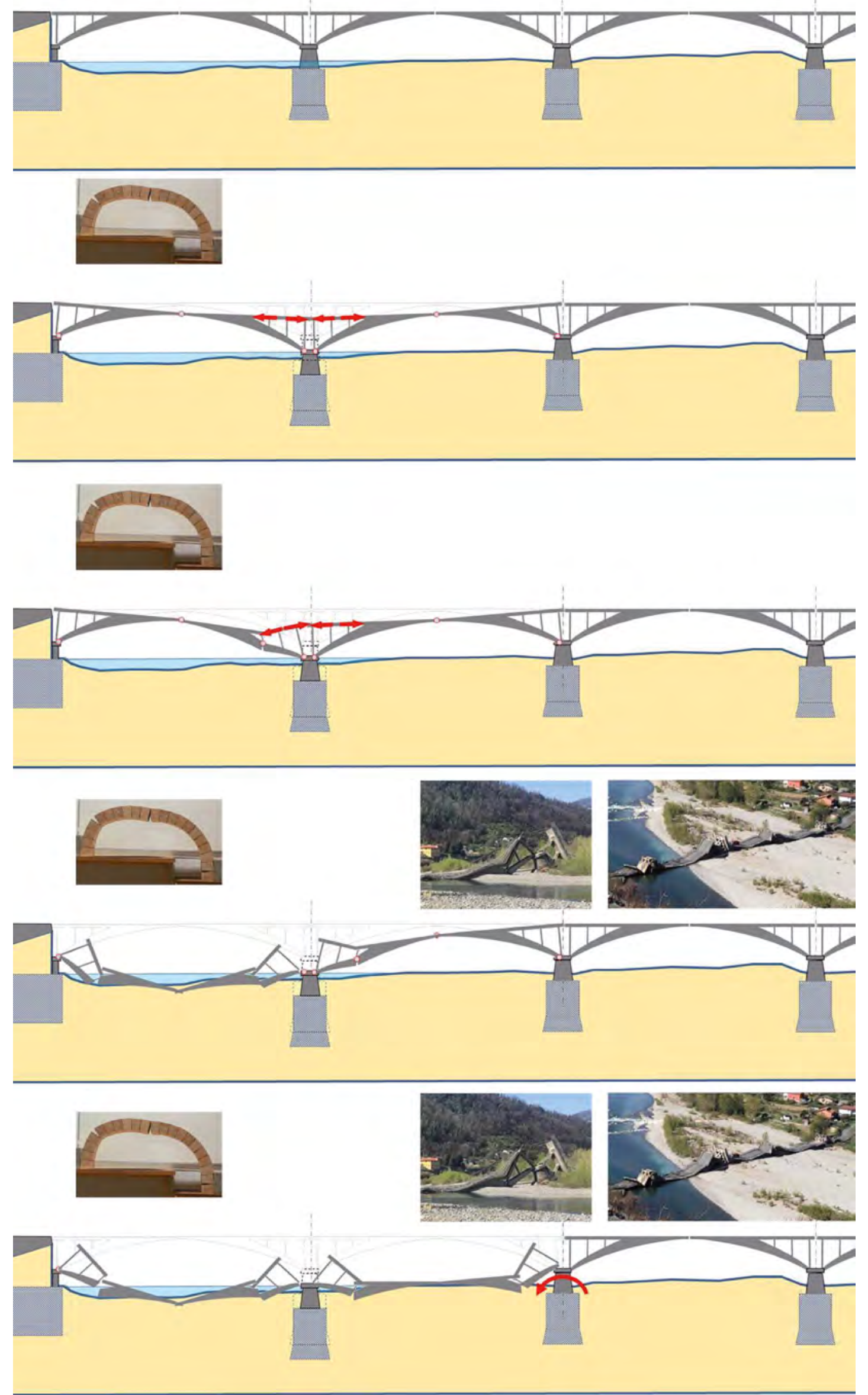

Figura 36. Hormigón lixiviado (ligante disuelto) y degradado en el puente de San Clodio, sobre el Sil. Trabajo de los autores en 2004. 
requiere de herramientas que, si bien es deseable se funden en procedimientos fenomenológicos con expresión analítica, no siempre el conocimiento ha llegado aún a esa simbiosis [26, 27 y 28]. Por lo tanto, deben progresar en paralelo las actuaciones de investigación básica y aplicada con los planteamientos más empiristas pero racionales como los que se muestran aquí.

En ese punto, los autores desean lanzar la idea de que las autopsias, que se realizan de oficio cuando se ha producido un accidente y se trata de identificar responsabilidades, deberían ser obligatorias, en ciertos casos, cuando las decisiones en las que se han fundado las órdenes de demolición necesitan un respaldo y, muy particularmente, pueden ser la base de estudios que permitan proyectar las enseñanzas que transmiten a otros puentes de edades, tipologías y clases de exposición semejantes. La medicina, que tanto ha progresado merced a las autopsias, enseña el camino a seguir en este fascinante mundo de la ingeniería de conservación (de los puentes existentes, obviamente). Pero esa es otra historia.

\section{Agradecimientos}

Los autores creen que este texto preparado le habría gustado a Luis $\mathrm{M}^{\mathrm{a}}$ Ortega Basagoiti, en cuyo homenaje se ha editado el presente número de Hormigón y Acero. Siempre con los pies en la tierra y la cabeza sobre los hombros, el entrañable Luis expresaba una sensibilidad especial hacia el aura del patrimonio construido, si se admite el término. Hacía gala, sin proponérselo, de un extraordinario sentido común desde el que, con modestia, como hacen los personajes de altura, sintetizaba las claves de la materia tratada en los debates a los que asistía. Entre esas claves están los riesgos no tan evidentes en puentes existentes. Así actuó en octubre de 2018, cuando el Colegio de Ingenieros de Caminos organizó una mesa redonda a propósito del accidente del puente Polcevera (también llamado Morandi), que causó un gran revuelo mediático y en la profesión. Los autores participaron con él en la preparación y en el desarrollo de aquella sesión, verdaderamente aleccionadora, cuyo eco parece ahora (2021) ya algo lejano.

\section{Referencias}

1. Corres-Peiretti, H., Ariñez-Fernández, F., Sánchez-Delgado, J. (2019). Model Code 2020: A fib Project for the advancement of structural concrete. Informes de la Construcción, 71(553): e275. https://doi. org/10.3989/ic.67477.

2. Comité de Puentes de carretera de la ATC-AIPCR. (2021) Grupo de trabajo sobre Valor patrimonial de los puentes. Recomendaciones para caracterizar el valor patrimonial de los puentes.

3. Tanner, P. (2016) Requisitos de seguridad estructural basados en los riesgos para las personas. Tesis doctoral dirigida por L. Albajar. ETSICCP-UPM.

4. White Paper on Risk Governance. Towards an integrative approach (2005). https://irgc.org/wp-content/uploads/2018/09/IRGC_WP_ No_1_Risk_Governance_reprinted_version_3.pdf

5. EN 1990:2002. Eurocódigo 0: Bases de proyecto. CEN/TC 250 Eurocódigos estructurales.
6. Tena, M. (2019) Fundamentos para la gestión del envejecimiento y conservación sostenible de las estructuras del patrimonio arquitectónico. Tesis doctoral, dirigida por J. León. ETSICCP-UPM.

7. Reglamento General de Circulación. Real Decreto 1428/2003, de 21 de noviembre, por el que se aprueba el Reglamento General de Circulación para la aplicación y desarrollo del texto articulado de la Ley sobre tráfico, circulación de vehículos a motor y seguridad vial, aprobado por el Real Decreto Legislativo 339/1990, de 2 de marzo.

8. del Cuvillo, A.; del Cuvillo, R. (2002) Trenes de carga en puentes de carretera. Revista de Obras Públicas. Septiembre, 149 (3424): 39-50.

9. Peña Boeuf, A. (1916) Puente de la presa (Navarra). Revista de Obras Públicas, 64, tomo I (2150): 629-636.

10. León, J., Corres, H., Prieto, F. (2008). Inspección y evaluación de estructuras existentes: una tarea para ingenieros valientes. Revista de Obras Públicas. 155 (3492): 29-38.

11. León, J. (2017). Algunas reflexiones acerca del trato dispensado a los puentes de piedra o ladrillo. Cap. 1 del libro Los puentes de piedra (o la drillo) antaño y hogaño. J. León y J. M. Goicolea, coordinadores. Lecciones Juanelo Turriano de Historia de la Ingeniería.

12. León. J., Pérez, A., Corres, H. (2007) Reflexiones sobre el valor pedagógico de la historia del hormigón estructural. Actas de las II Jornadas de Enseñanza del Hormigón Estructural. ACHE. Noviembre de 2007.

13. del Cuvillo, R. (2007) Colecciones oficiales de obras de paso de carreteras. siglos XIX y XX. Madrid: Colegio de Ingenieros de Caminos, Canales y Puertos.

14. del Cuvillo, R., Galindo, J. (1988) Inspecciones principales de puentes de carretera. Ministerio de Obras Públicas y Transportes.

15. https://www.pinterest.com.mx/pin/469922542349200837/

16. El Correo, 18 de noviembre de 2019. https://www.elcorreo.com/ internacional/union-europea/puente-colgante-derrumba-francia-20191118110532-ntrc.html

17. Peña, B., Berruezo, P., León, J. (2017) Colapso del puente del Guadarrama en la M-527. Autopsia y enseñanzas. Rutas. Revista de la Asociación Técnica de Carreteras. Número 170: 20-33.

18. ATEP. Hormigón Pretensado. Realizaciones Españolas. Serie de publicaciones de carácter aproximadamente trienal iniciada en 1970.

19. https://www.ilmessaggero.it/video/primopiano/lecco_momento_cro1lo_cavalcavia-2052339.html

20. Calavera, J. (1996) Patología de estructuras de hormigón armado y preten sado. Madrid: INTEMAC.

21. Espeche, A., León, J. (2011) Estimation of bond strength envelopes for old-to-new concrete interfaces based on a cylinder splitting test. Construction and Building Materials 25: 1222-1235.

22. Jerez, E., León, J., Martín-Caro, J.A. (2007) Inspección y diagnosis de puen tes ferroviarios. Fábrica, acero y hormigón. Madrid: ADIF.

23. León, J. (2017) Proyecto y construcción de puentes de fábrica. Cap. 8 del libro Los puentes de piedra (o ladrillo) antaño y hogaño. J. León y J. M. Goicolea, coordinadores. Lecciones Juanelo Turriano de Historia de la Ingeniería.

24. León, J., Corres, H., Pérez-Fadón, S., Herrero, J.E., Rodríguez, F., Prieto, F. (2008) Lifespan evaluation of 8 bridges of the Indiana Toll Road. A case study. Actas de IALCCE'08. First International Symposium on Life-Cycle Civil Engineering. Varenna, Lake Como, Italy: Eds. Fabio Biondini \& Dan M. Frangopol.

25. https://www.google.com/search? q=morandi+polcevera\&source $=1 \mathrm{n}$ ms\&tbm=isch\&sa=X\&ved=0ahUKEwiYr-zoofDeAhXFyqQKHWxSCmEQ_AUIDigB\&biw=1703\&bih=786\#imgrc $=$ Y78-W9KJXzLRXM:\&s$\mathrm{pf}=1543173628755$

26. Petroski, H. (2009) Paradigmas de diseño. Casos históricos de error y buen juicio en Ingeniería. Madrid: Modus Laborandi.

27. Scheer, J.(2010) Failed bridges. Case studies, causes and consequences. Ernst \& Sohn.

28. Ley, J. González Valle, E. (2012) Los accidentes de los puentes: errores de ayer y de hoy, lecciones para el mañana. Cuadernos INTEMAC $1^{\text {er }}$ trimestre de 2012. 